IZA DP No. 5729

A Panel Data Analysis of Racial/Ethnic Differences in Married Women's Labor Supply

Kenneth R. Troske

Alexandru Voicu

May 2011 


\title{
A Panel Data Analysis of Racial/Ethnic Differences in Married Women's Labor Supply
}

\author{
Kenneth R. Troske \\ University of Kentucky \\ and IZA \\ Alexandru Voicu \\ CUNY College of Staten Island \\ and IZA
}

Discussion Paper No. 5729
May 2011

IZA

P.O. Box 7240

53072 Bonn

Germany

Phone: +49-228-3894-0

Fax: +49-228-3894-180

E-mail: iza@iza.org

Any opinions expressed here are those of the author(s) and not those of IZA. Research published in this series may include views on policy, but the institute itself takes no institutional policy positions.

The Institute for the Study of Labor (IZA) in Bonn is a local and virtual international research center and a place of communication between science, politics and business. IZA is an independent nonprofit organization supported by Deutsche Post Foundation. The center is associated with the University of Bonn and offers a stimulating research environment through its international network, workshops and conferences, data service, project support, research visits and doctoral program. IZA engages in (i) original and internationally competitive research in all fields of labor economics, (ii) development of policy concepts, and (iii) dissemination of research results and concepts to the interested public.

IZA Discussion Papers often represent preliminary work and are circulated to encourage discussion. Citation of such a paper should account for its provisional character. A revised version may be available directly from the author. 


\section{ABSTRACT \\ A Panel Data Analysis of Racial/Ethnic Differences in Married Women's Labor Supply}

We study differences in life-cycle labor supply among white, black, and Hispanic women, focusing on the interaction between race/ethnicity, education, and fertility. We use panel data that capture women's labor market and fertility histories and an econometric model that accounts for the endogeneity of labor market and fertility decisions, the heterogeneity of the effects of children and their correlation with the fertility decisions, and the correlation of sequential labor market decisions. Our results show an intricate connection between race/ethnicity, education, and fertility as determinants of women's life-cycle labor supply. For all levels of education, white women have fewer children, have the first birth later in life, and space subsequent births more closely together. The level of labor market involvement before the first birth is highest for white women and lowest for Hispanic women, but children reverse the relationship between race/ethnicity and level of labor market involvement. The negative effects of children are largest for white women and smallest for Hispanic women, and as a result, among women with two children, black and Hispanic women work more than white women. Racial/ethnic differences in fertility decisions, pre-natal labor supply, and labor supply responsiveness to children decline with the level education. Educational differences contribute to the racial/ethnic differentials in labor supply. White women have the highest levels of education and Hispanic women have the lowest levels of education. Other things equal, women with higher education have fewer children, have the first birth later in life, space subsequent births more closely together, work more before the birth of the first child, but face larger negative effects of children on their level of labor market involvement.

JEL Classification: $\quad \mathrm{C} 11, \mathrm{C} 15, \mathrm{~J} 13, \mathrm{~J} 22$

Keywords: racial/ethnic differentials in female labor supply, education, endogenous fertility decisions, heterogeneous children effects, multinomial probit model, Gibbs sampler

Corresponding author:

Alexandru Voicu

College of Staten Island

The City University of New York

2800 Victory Boulevard

Staten Island, NY 10314

USA

E-mail:voicu@mail.csi.cuny.edu 


\section{Introduction}

In the 1950s and 1960s, in the US, black women worked more than white women. The employment gap appeared set to widen if the trends seen in the 1960s-the growth in the aggregate employment of women and the improvement of the opportunities available to younger and better educated black women - were to continue (Bell, 1974). However, the economic crises of the 1970s and the industrial restructuring that followed, as well as the expansion of welfare programs, affected adversely the employment of black women. This led to the narrowing and, eventually, the reversal of the racial employment gap. In the early 1980s, for the first time in history, the employment rates of white women surpassed the employment rates of black women. The racial differences in employment continued to grow until the mid 1990s. Even though welfare reform and the overall economic growth of the 1990s led to higher employment rates among black women, the gap remained significant (England, Garcia-Beaulieu, Ross, 2004).

Changes in the sign and the magnitude of the racial employment differentials were accompanied by changes in their determinants. Studies using data from the 1950s (Cain, 1966, and Bowen and Finegan, 1969) found that the racial employment gap was explained in part by higher incidence of part time among black women and in part by differences in observed characteristics (housing conditions, marital stability, employment prospects of spouses). During the following decade, the employment gap widened in favor of black women. Differences in the level of labor market involvement of participants no longer mattered, as black women were also more likely to work full time. More importantly, as Bell (1974) showed in his seminal paper, differences in observed characteristics could not explain the employment gap. Instead, there were fundamental differences between the labor supply of black and white women which stem from different responses to given characteristics. Quality of residence, marital stability, spouse's employment prospects, education, and the presence of young children in the household affect differently the labor force participation decisions of black and white women: black women who work were selected among those with better socio-economic characteristics whereas the reverse was true for white women.

Subsequent studies in both economics and sociology (Lehrer, 1992, Young-Hee Yoon and Linda J. Waite, 1994, Karen, 1996, Browne, 1997, Cohen and Bianchi, 1999, Corcoran, 1999, England, Garcia-Beaulieu, Ross, 2004) added depth to the picture of racial employment differentials by focusing on the role of the most important determinants. They also broadened the scope of the analysis by investigating employment differentials among white, black, and Hispanic women. These studies provide two important insights. First, the increase in women's labor force participation, which forms the background for the reversal of the racial employment gap, was driven mainly by the expansion of job market opportunities available to women with higher education, and to a smaller degree by "push" factors such as the decline in male employment and earnings. As a result, the benefits of employment accrue disproportionately to women from more privileged groups with respect to race/ethnicity, education, and family background (Corcoran, 1999). ${ }^{1}$ Second, racial/ethnic employment differences are explained in great part by differences in educational attainment and completed fertility and by differences in the effects of education on labor supply and in labor supply responsiveness to children. Differences in factors like marital status and the spouse's employment prospects matter less and their importance has declined over time.

\footnotetext{
${ }^{1}$ This finding is consistent with results of Goldin (1990), who shows that married women's labor force participation has become less responsive to their husband's earnings, and of Juhn and Murphy (1997), who point out that even though the aggregate growth in women's labor force participation appears to compensate for the decline in male earnings, employment gains accrued mostly to women whose husbands are highly educated and have high income.
} 
Previous studies, however, employ analytical frameworks that overlook several important issues in the estimation of labor supply. Most use cross-sectional data that do not provide reliable estimates of the way in which life-cycle labor supply varies across racial/ethnic groups and levels of educational attainment, or of the way in which fertility interacts with race/ethnicity and education as determinants of life-cycle labor supply. In addition, even though differences in fertility decisions and in labor supply responsiveness to children are important determinants of racial/ethnic employment differentials, the econometric models which are generally used (e.g., OLS regression or multinomial logit estimated with cross-sectional data) do not take into account the three main problems inherent in studying the connection between fertility and labor market decisions. First, labor market and fertility decisions are endogenous as the number of children and the timing and spacing of births are controlled, at least in part, by women. Second, sequential labor market decisions are correlated and, therefore, maternity-related work interruptions or reductions in the level of labor market involvement affect labor supply in subsequent periods. Third, the effects of children on labor supply are heterogeneous and are correlated with the fertility decisions. Heterogeneous preferences for market work and for children influence pre-market and early career investments in human capital, which, in turn, affect the opportunity cost of children. Together, heterogeneous preferences and correlated, heterogeneous opportunity costs of children jointly determine women's fertility and labor market decisions. As recent literature on treatment effects ${ }^{2}$ indicates, if the effects of children are heterogeneous and if individuals act on the basis of those differences, the average effect underestimates the effect of additional children for those who choose not to have them and overestimates it for those who had the children.

The goal of this paper is to examine the interaction between race/ethnicity, education, and fertility as determinants of married women's life-cycle labor supply. We do so in a framework that explicitly accounts for endogeneity of labor market and fertility decisions, for the heterogeneity of the effect of children on labor supply, for the correlation between the effect of children and subsequent fertility decisions, and for the correlation of sequential labor market decisions. Sequential labor market decisions and fertility decisions are jointly modeled in a mixed-effects simultaneous equation framework. Correlated individual-specific random coefficients included in labor market and fertility equations capture the variation in labor market and fertility behavior across race/ethnicity and education, the heterogeneity of the effects of children on the level of labor market involvement, as well as the correlation between the effects of children on labor supply and fertility behavior.

We focus on married women for several reasons. First, underlying theoretical models of time allocation (like Mincer, 1962, Becker, 1965, Willis, 1973, Michael, 1973, Leibowitz, 1974, Gronau, 1977, Angrist and Evans, 1998) and dynamic models of fertility (like Happel et al., 1984, Moffit, 1984, Heckman and Willis, 1975, Wolpin, 1984, Newman, 1988, Hotz and Miller, 1988, Cigno and Ermisch 1989, Walker, 1995) are household models. Second, married women, specially married women with children, have driven the dramatic change in the labor supply behavior among women that took place over the past few decades (Blau, 1998, Blau, Ferber, and Winkler, 1998, Leibowitz and Klerman, 1995). Third, as Cohen and Bianchi (1999) point out, the growth in labor force participation of married women provides a context in which expectations are formed for single mothers. Identifying whether this trend has been primarily generated by expanding opportunities or by "push" factors informs the debate over whether single mothers on welfare should be driven into the labor force.

We estimate the model using Markov chain Monte Carlo (MCMC) methods and panel data from

\footnotetext{
${ }^{2}$ Heckman and Robb (1985), Bjorklund and Moffitt (1987), Imbens and Angrist (1994), Heckman and Vytlacil (1999, 2000, 2001), Carneiro, Heckman, and Vytlacil (2001), Moffitt (2005).
} 
1979 National Longitudinal Survey of Youth (NLSY79). We use the NLSY79 data because they provide a fairly complete picture of both these women's labor market and fertility histories and contain a rich set of family background variables. In addition, the individuals in the panel, with ages between 14 and 21 years old in 1979, represent the generation that has driven the reversal and subsequent widening of the racial employment gap.

Our results show an intricate connection between race/ethnicity, education, and fertility as determinants of women's life-cycle labor supply. For all levels of education, white women have fewer children, have the first birth later in life, and space subsequent births more closely together. The level of labor market involvement before the first birth is highest for white women and lowest for Hispanic women, but children reverse the relationship between race/ethnicity and level of labor market involvement. The negative effects of children are largest for white women and smallest for Hispanic women, and as a result, among women with two children, black and Hispanic women work more than white women. Racial/ethnic differences in fertility decisions, pre-natal labor supply, and labor supply responsiveness to children decline with the level education. Educational differences contribute to the racial/ethnic differentials in labor supply. White women have the highest levels of education and Hispanic women have the lowest levels of education. Other things equal, women with higher education have fewer children, have the first birth later in life, space subsequent births more closely together, work more before the birth of the first child, but face larger negative effects of children on their level of labor market involvement.

The remainder of the paper is structured as follows. In the next section, we discuss the theoretical background of our empirical approach. In section 3 we describe the construction of the panel data set used in the estimation and provide a preliminary, non-parametric analysis of the way in which relationship labor market and fertility decisions vary among white, black, and Hispanic women. In section 4 we present the econometric model, the estimation procedure, and the design of the simulations. In section 5 we present the results of the empirical analysis. In section 6 we summarize the main results and discuss their implications.

\section{Theoretical Background}

Theoretical household models of time allocation (Mincer, 1962, Becker, 1965, Willis, 1973, Michael, 1973, Leibowitz, 1974, Gronau, 1977, Angrist and Evans, 1998) provide an ideal framework for studying educational differences in married women's labor supply responsiveness to children. In these models, families maximize inter-temporal utility functions defined over a set of commodities which includes the number and the quality of children (the utility-generating characteristic of a given child). The utility-generating commodities are produced at home with combinations of goods and services purchased on the market and the time inputs of household members. Utility is maximized subject to the wealth constraint, which equates life-time income with expenditure on utility-generating commodities evaluated at their respective opportunity costs. The solution to the optimization problem entails the demand functions for the utility-generating commodities and the optimal allocation of household members' time among leisure, market work, and home production. On the supply side, the optimal allocation of time allows predictions about the effects of changes in wage offers, in non-labor income, in productivity of time spent in home production, and in the number of children on the supply of time to the market, on leisure, and on time spent in home production.

Three factors affect the solution of this optimization problem: preferences, home production functions for the utility generating commodities, and wage offers. Before the birth of the first child, 
stronger preferences for utility-generating commodities that are goods-intensive, lower productivity in the home production of utility-generating commodities, and higher wages are associated with higher levels of labor market involvement. When a child is born, women start reallocating leisure, market time, and time spent in the home production of commodities unrelated to children to the production of child-related, utility-generating commodities. The transfer continues until the marginal product of time spent in the home production of child care is equal to either the wage or the marginal product of time spent in the home production of commodities unrelated to children. Stronger preferences for child quality, higher marginal product of own time in the production of child quality, and lower wages are associated with a larger effect of the child on the mother's labor supply.

The goal of this paper is to examine the interaction between race/ethnicity, education, and fertility as determinants of women's life-cycle labor supply. The channels through which education shapes the connection between fertility and labor market outcomes are well established. Education raises market productivity and, therefore, leads to higher wage offers, which in turn raise women's pre-natal level of labor market involvement and reduce the effects of children on their labor supply. Human capital investments that raise market productivity may also raise productivity in home production of child quality, which leads to larger effects of the children on the mother's labor supply. There is, however, little theoretical guidance on how wages and home productivity vary across race/ethnicity, once we control for education.

In addition, estimating the effect of children on labor supply is challenging for several reasons. First, labor market and fertility decisions are endogenous, as the number of children and the timing and spacing of births are controlled, at least in part, by women. Second, sequential labor market decisions of women are correlated and, as a result, labor market interruptions or temporary reductions in the level of labor market involvement are associated with lower employment probability in subsequent periods. There are multiple sources of correlation. Human capital theory predicts that skills accumulated through experience raise the probability of working in the future. Fixed costs of entering the labor force make future participation more likely for individuals already working. Job matching models where employers and employees learn about the quality of the match induce state dependence even if there is little investment in firm-specific human capital. Periods of nonparticipation or low level of labor market involvement are associated with lower levels of investment in human capital, or even depreciation of the human capital stock, loss of information on the quality of the match, and costly search for a new job.

Third, the effects of children on labor supply are heterogeneous and are correlated with the fertility decisions (the number of children and the timing and spacing of births). Preferences for children and utility-generating commodities unrelated to children differ across individuals. Other things equal, women with stronger preferences for commodities unrelated to children will choose to have fewer children and have them later in life to minimize their cost, will spend more time in market work, and will enjoy less leisure time. Other things are not equal, however. Women with stronger preferences for commodities unrelated to children may find it optimal to pursue higher levels of pre-market and early-career investments in human capital. These investments produce different production possibilities curves and different opportunity costs of children for women with different preferences. They raise market productivity and, therefore, lead to higher wage offers; they may also affect productivity in childcare, if, for example, women with higher education can better produce child quality, and the productivity in home production of utility-generating commodities unrelated to children. Together, heterogeneous preferences and heterogeneous opportunity cost of children determine the distribution of optimal fertility decisions (the number of children and the 
timing and spacing of births) and their connection with the dynamics of the level of labor market involvement.

In this paper we model sequential labor market and fertility decisions in a mixed-effect simultaneousequation framework. The mixed-effect framework allows us to examine the interaction between race/ethnicity, education, and fertility as determinants of women's life-time labor supply, while simultaneously addressing the main theoretical concerns inherent in the estimation of the effect of children on labor market behavior: the endogeneity of labor market and fertility decisions, the dependence of sequential labor market and fertility decisions, the heterogeneity of the effects of children on labor supply, and the correlation between these effects and fertility decisions.

\section{Data}

We use panel data from the 1979 National Longitudinal Survey of Youth (NLSY79). The NLSY79 contains a representative sample of individuals who were between 14 and 21 years old in 1979 . Individuals were surveyed every year between 1979 and 1994, and every other year thereafter. For the purpose of our study, NLSY79 has two important features. First, it contains detailed information on respondents' labor supply history. Second, it contains information on the birth dates of respondents' children and on the beginning and end dates of respondents' marriages. Using this information, we constructed complete labor market, marital status, and fertility histories for each individual.

We use data from the nonmilitary sample of the 1979-2004 surveys. ${ }^{3}$ Since we focus on the labor supply of married women, we restrict the sample to women who are not married and are childless in 1979, get married after 1979, remain married until 2004, only have children while married, and only have biological children in the household over the period of our data (this latter criteria eliminates women who adopt children or who marry men who have children who live with them). In order to abstract from the trade-off between schooling and working, we only consider a woman at risk to work or to have a child once she has been out of school for at least 18 months continuously (once a women leaves school we consider her still at risk even if she returns to school). Finally, we require at least five years of data for each woman.

Imposing these strict selection criteria (especially the continuous marriage requirement) reduces the sample size, circumscribes the scope of our research to a narrower set of experiences and, potentially, leads to non-random selection of individuals with respect to unobserved traits that are relevant to their labor market and fertility behaviors. We impose these restrictions for two reasons. First, the focus on married women is very common in the literature studying the relationship between children and women's labor supply (e.g., see Carrasco, 2001, Hyslop, 1999, Angrist and Evans, 1998, Heckman and Willis, 1977) because married women, especially married women with children, have driven the dramatic change in the labor supply behavior among women that took place over the past few decades (Blau, 1998, Blau, Ferber, and Winkler, 1998, Klerman and Leibowitz, 1994). In addition, as Cohen and Bianchi (1999) point out, the growth in labor force participation of married women provides a context in which expectations are formed for single mothers. Identifying whether this trend has been primarily generated by expanding opportunities or by "push" factors informs the debate over whether single mothers on welfare should be driven into the labor force. Our sample is in a way more informative than those used in previous studies using panel data

\footnotetext{
${ }^{3}$ We exclude women who live on a farm larger than 100 acres at any point in the period because it is difficult to identify hours worked for individuals living on a farm.
} 
(e.g. Hyslop, 1999, and Carrasco, 2001) which contain women who are continuously married or cohabitating for the entire duration of the sample. Our panel is significantly longer and, since we begin following these individuals when they enter the labor market, we observe their level of labor market involvement both before and during marriage. ${ }^{4}$ Second, the dynamic specification of the econometric model we propose requires us to account for the distribution of the number of children in the initial period. The way in which we select our sample ensures that the number of children in the initial period is identical, zero, for all individuals in our sample.

Tables 1 and 2 provide an overview of the variables used in the analysis. Panel A of table 1 presents summary statistics, by year, for the time-varying personal characteristics used in the analysis. Column 2, which presents the number of women considered at risk in a given year, shows the unbalanced nature of the data. In 1979 only 116 women are considered at risk, by 1997 all 645 women are considered at risk. Column 3 shows the proportion of women at risk that are married. Husband's income and income from other sources (columns 4 and 5 show averages per woman at risk) have been deflated using the CPI-U and are in 1979 dollars. Since after 1994 NLSY79 was conducted every other year, we imputed observations for the post-1994 missing years as well as several missing observations from the available years; our exact imputation procedure is described in the data appendix. Column 6 shows the yearly birth rates and columns 7 to 9 show the average number of children by age category, for women at risk. No women had any children prior to 1981. In the last years of the panel, birth rates are very low, which indicates that our data capture complete fertility histories for most women in the sample. In 2003, the average number of children was 1.8, and the average numbers of children for each age category were 0.05 for ages 0 to $1,0.14$ for ages 2 to 4 , and 1.61 for 5 years older.

The distribution of the labor market states is showed in columns 10 to 13 . To be considered working a woman must have both positive hours worked and positive income. Women who worked more than 1750 hours in a year are classified as full time. Women who work between zero and 1750 hours, but who work on average more than 35 hours a week, are considered full time part year. Women who work between zero and 1750 hours, but who work on average less than 35 hours a week, are considered part time (we imputed missing observations on the number of hours worked for several individuals; the imputation procedure is described in the data appendix). Women who work zero hours or who have zero income are considered not working. The percentage of women working full time and working full time part year declines over time while the percentage of women not working rises. The percentage of women working part time remains fairly constant.

\footnotetext{
${ }^{4}$ We have carefully considered the possibility of using a sample that did not impose the marriage-related restrictions. We have decided not to pursue this avenue for several reasons. At the most basic level, a binary variable can capture the difference between single and married status, but it is inappropriate for describing marital histories of individuals who divorce or have multiple marriages - a nested categorical variable would be necessary. Second, marital status affects not only the level of labor market involvement, but also the effects of children on the level of labor market involvement. In the setting of our model this would mean adding interactions between the children variables and the variables describing marital status and, accordingly, expanding the layer of random effects that capture the role of time-invariant personal characteristics and individual level heterogeneity. Finally, removing marriage-related sample selection restrictions makes endogenous modeling of marital status more stringent. Technically, the Markov chain Monte Carlo techniques we employ in this paper provide an estimation framework flexible enough to model another binary variable, like marital status, endogenously. In practice, however, even if the binary variable provided an accurate representation of marital histories, we would be hard-pressed to find valid instruments. In addition, a significantly larger sample and a larger number of equations translate into significantly higher computational costs.

To test the robustness of our results to sample selection, however, we estimated our model with a sample that did not impose the marriage-related restrictions. While the average level of labor market involvement is lower in this larger sample, the qualitative results regarding the effect of children on the level of labor market involvement hold.
} 
Panel B presents summary statistics for the time-invariant personal characteristics and family background variables that are used as observed sources of heterogeneity: education, race, labor market status of respondent's mother, and parents' education. Thirty-six percent of the women in the sample have 12 years of education or less, 27 percent have between 13 and 15 years of education, while 37 percent have 16 years of education or more. Seventy percent of our sample is white, with the remainder evenly split between Hispanic and black. About $1 / 3$ of respondents' mothers worked full time and 1/3 did not work at all. For 75 percent of the sample neither parent has a college education, for 16 percent one parent has college education, and for 9 percent both parents have college education.

Table 2 shows the differences in level of education, completed fertility, and timing of the first birth among white, black, and Hispanic women. White women have higher levels of education than both black and Hispanic women. Among white women 42.6 percent have 16 years of education or more, compared with 32.6 percent of black women 16.2 percent of Hispanic women. The percentages of women with 13-15 years of education are larger for black and Hispanic women (38.2 for black women and 36.2 percent for Hispanic women compared with 22.2 percent for white women). The percentage of women with 12 years of education or less is largest for Hispanic women, 47.6, compared with 35.3 for white women and 29.2 for black women. Hispanic women have more children than both white and black women. The average number of children is 1.81 for white women, 1.46 for black women, and 2.09 for Hispanic women. White women postpone the first birth more than black and Hispanic women. On average, white women have the first birth 3.341 years after marriage, black women have the first birth 3.077 years after marriage, and Hispanic women have the first birth 2.685 years after marriage. ${ }^{5}$

Figure 1 presents the dynamics of the labor force status in the years surrounding birth for women who have one child by 2003. Prior to birth, 80 percent of women work full time, with the rest either working part time or full time part year. Very few women do not work at all. One of the primary effects of children on women's labor supply is through the number of hours worked. In the year of the birth the percentage of women working full time drops considerably, while there is a jump up in the percentage working full time part year and modest increase in the percentage working part time or not working. After birth the percentage of women working full time part year returns to the pre-birth level while there is a continual increase in the percentage of women in all other labor market states. The spike in the probability of working full time part year in the year of the first birth suggests that a large percentage of women work full time before the birth and stop working for a relatively short period around birth; many women return to full-time work the year after the birth; roughly equal shares find part-time working arrangements or do not return to work after birth.

\section{Econometric Framework}

The goal of the econometric model we propose is to capture the variation in labor market and fertility behavior, as well as in the effects of children on the level of labor market involvement, across race/ethnicity and education, in a framework that simultaneously addresses the three key issues in the estimation of the effects of children on labor supply - the endogeneity of labor market and

\footnotetext{
${ }^{5}$ Empirical studies that document changes in fertility patterns use age of the first birth as a measure of timing. Our measure is consistent, however, with the setup of the dynamic models of fertility decisions (Hotz et al., 1997) in which the timing of the first birth is measured in terms of household "age."
} 
fertility decisions, the heterogeneity of the effects of children on labor supply and their correlation with fertility decisions, and correlation of sequential labor market decisions.

\subsection{The Model}

We represent the labor market decisions using a model with four states - full time (FT), full time part year (FP), part time (PT), and nonwork (NW). This model provides a more accurate description of the level of labor market involvement than the two- or three-state models previously used in the literature. As we showed, a majority of women work full time before the birth of the first child. However, there is substantial variation in women's labor supply after birth with some women returning to full-time work, some switching to part-time and some choosing to remain out of the labor market for an extended period. In a two-state model (work, nonwork) in which labor market states are defined using hours worked in a given year, women who return to full-time work after short birth-related interruptions will be treated the same as women who switch to part-time work. Therefore, the two-state model does not capture the variation in the number of hours, which may represent a significant share of the effect of children. A three-state model (full-time, part-time, and nonwork) inaccurately classifies many of the years in which birth-related interruptions occur as part time when they are combinations of full-time work and inactivity (paid and unpaid leave). This will make it appear as if women are transiting to part-time work in the year of the birth of a child when, in fact, they are actually leaving the labor market. This in turn will make it appear as if part-time work is less persistent.

We model sequential labor market decisions using a multinomial probit model with autocorrelated error terms. Fertility decisions are modeled using a probit model with state-dependence and auto-correlated error terms. Labor market decisions and fertility decisions are driven by a sequential optimization process. At the beginning of each period an individual chooses the level of labor market involvement for the current period and simultaneously makes a fertility decision. The level of labor market involvement is selected from the set of four alternatives, by comparing the utility associated with each state. The value functions associate with each state are denoted by $U_{i t}^{F T}, U_{i t}^{F P}, U_{i t}^{P T}$, and $U_{i t}^{N W}$, where the subscript $i$ indicates individuals, $i=1, \ldots, N$ the subscript $t$ indicates time periods, $t=1, \ldots, T_{i}$ and the superscripts denote the labor market state. Since the choice of a level of labor market involvement depends only on differences of value functions, we transform the model by considering only values relative to the nonwork state. The fertility decision is whether to conceive a child during the current period. Fertility choices are made by comparing the value functions corresponding to having and not having a child. We denote the difference between these value functions $U_{i t}^{F}$. The transformed value functions that drive the labor market and fertility decisions have the following specifications:

$$
\begin{gathered}
U_{i t}^{1}=U_{i t}^{F T}-U_{i t}^{N W}=K_{i t} \alpha^{1}+X_{i t}^{L M} \beta^{1}+Z_{i t}^{1} \gamma+\left(K_{i t} * Z_{i t}^{1}\right) \delta+\sum_{m} K_{i t} \theta_{m l(i, m)}^{1}+u_{i t}^{1} \\
U_{i t}^{2}=U_{i t}^{F P}-U_{i t}^{N W}=K_{i t} \alpha^{2}+X_{i t}^{L M} \beta^{2}+Z_{i t}^{2} \gamma+\left(K_{i t} * Z_{i t}^{2}\right) \delta+\sum_{m} K_{i t} \theta_{m l(i, m)}^{2}+u_{i t}^{2} \\
U_{i t}^{3}=U_{i t}^{P T}-U_{i t}^{N W}=K_{i t} \alpha^{3}+X_{i t}^{L M} \beta^{3}+Z_{i t}^{3} \gamma+\left(K_{i t} * Z_{i t}^{3}\right) \delta+\sum_{m} K_{i t} \theta_{m l(i, m)}^{3}+u_{i t}^{3} \\
U_{i t}^{F}=K_{i t} \alpha^{F}+X_{i t}^{F} \beta^{F}+\sum_{m} K_{i t}^{F} \theta_{m l(i, m)}^{F}+u_{i t}^{F}
\end{gathered}
$$

We construct the fertility variable (whether a child is conceived during the current period) from data on children's birth dates and we do not consider pregnancies that end in miscarriage, stillbirth, or abortion. ${ }^{6}$ This specification is a departure from the previous literature which primarily used

\footnotetext{
${ }^{6}$ NLSY 79 contains information on the number of pregnancies ending in miscarriage, stillbirth, or abortion but
} 
the occurrence of a birth to describe fertility decisions. Our specification rests on the premise that time-varying personal characteristics and variables describing a woman's relevant socioeconomic environment affect the fertility process through the conception decision, rather than through the birth of the child.

The vector $K_{i t}$ contains a constant term and variables describing the number of children in three age categories $(0-1,2-4,5$ and older), where age is measured at the last birthday. The variables describing the number of children and their age distribution are included in the participation equation in order to capture the effect of children on the level of labor market involvement. These variables which describe the entire history of fertility decisions - how many children have been born and how far in the past - are also included in the fertility equation, thus making current fertility decisions a function of past fertility decisions. The inclusion of the variables describing the number of children and their age distribution, together with the autocorrelated error term, helps us capture the timing and the spacing of births.

$X_{i t}^{L M}$ is a vector of personal characteristics relevant to labor market decisions that includes marital status, spouse's wage, other income, the region of residence (North East, North Central, South, and West), and whether the respondent resides in an urban or rural area. $X_{i t}^{F}$, is a vector of personal characteristics relevant to fertility decisions that includes other income, the region of residence, whether the respondent resides in an urban or rural area, and the number of siblings with children.

$Z_{i t}^{1}, Z_{i t}^{2}, Z_{i t}^{3}$ are expected hourly wages in each of the alternative labor market states. We include expected wages in the participation equations both by themselves, to capture the way in which they affect the level of labor market involvement, and in interaction with the variables describing the number and age distribution of children, $\left(K_{i t} * Z_{i t}^{1}\right),\left(K_{i t} * Z_{i t}^{2}\right),\left(K_{i t} * Z_{i t}^{3}\right)$, to describe the way in which the effect of children varies with the wage. ${ }^{7}$ We use the observed hourly wage for the current labor market state and impute the hourly wage for the alternative states. The imputation is based on a standard wage regression and is estimated using all women in the NLSY between 1979 and $2004 .^{8}$

We do not include wages in the fertility equation. However, since wages affect the values of alternative levels of labor market involvement, and since we allow the value functions corresponding to labor market decisions to be correlated with the value function corresponding to the fertility decision, wages will affect fertility decisions in our framework.

We also do not include marital status or spouse's wage in the fertility equation because our data only includes women who have children while married. We do not include respondent's age in the specification of the labor market and fertility decisions. Since we account for the dependence of sequential labor market and fertility decisions by specifying AR(1) structures for the error terms of the four equations, the effect of age cannot be identified. However, it is unlikely our results will be affected by significant age effects since the age range in our sample is only seven years.

The mixed-effect structure, which combines fixed and random coefficients, allows us to study

not on the date those pregnancies begin. In addition, the likelihood of termination could be correlated with labor supply decisions.

${ }^{7}$ It is important to note that expected wages and the interaction terms between expected wages and the children variables vary over $i, t$, and labor market state, and their coefficients are constrained to be the same across states. Keane (1992) and Geweke, et al. (1997) point out that the inclusion of variables whose values differ across alternative choices and whose coefficient is constrained to be the same across states is important in the identification of multinomial probit models such as this, which would otherwise be difficult due to flat spots in the likelihood function.

${ }^{8}$ The regression includes second degree polynomials of years of education and experience, a full set of interactions between the terms of these polynomials and the labor market states, and the urban and region dummy variables. 
how the number of children, the timing and spacing of births, and the relationship between fertility and labor market behavior varies across time-invariant personal characteristics like education, race, and family background characteristics, and, controlling for these variables, to assess the role of individual-level heterogeneity. The $\alpha^{\prime} s, \beta^{\prime} s, \gamma$ and $\delta^{\prime} s$ in our model are vectors of global (fixed effect) parameters which are common across individuals in the sample. We allow four $(m=1, \ldots, 4)$ independent sources of heterogeneity to affect individuals' decisions: individuals' time invariant personal characteristics (interaction between race and education), family background variables related to tastes for work and family (the labor market status of respondent's mother and the education levels of respondent's parents), and individual-level heterogeneity. Each source of heterogeneity has $l_{m}$ levels. We have nine levels for the interaction between race and education and race (white, black, and Hispanic women with three possible levels of education, 12 years or less, white women with 1315 years, 16 years or more), two for respondent's mother's labor market status (full time and other) and three for parents' education (none of the parents, one, or both parents have college education); the number of levels for individual-level heterogeneity is equal to the number of individuals in the sample. Each individual in the data is assigned a level for each source of heterogeneity $l(i, m)$.

To level $l$ of heterogeneity source $m$ corresponds the vector of random coefficients $\theta_{m l}=$ $\left[\theta_{m l}^{1^{\prime}}\left|\theta_{m l}^{2^{\prime}}\right| \theta_{m l}^{3^{\prime}} \mid \theta_{m l}^{F^{\prime}}\right]$. The four components of $\theta_{m l}, \theta_{m l}^{1^{\prime}}, \theta_{m l}^{2^{\prime}}, \theta_{m l}^{3^{\prime}}, \theta_{m l}^{F^{\prime}}$, correspond to the four equations of the model. Each component includes four elements, one random effect and three random coefficients, corresponding to the four variables in the vector $K_{i t}$. We assume $\theta_{m l}$ are normally distributed, independent across the $l_{m}$ levels of heterogeneity of source $m, \theta_{m l} \sim \operatorname{MVN}\left(0, D_{m}\right)$, independent across sources of heterogeneity, and uncorrelated with the regressors $X_{i t}^{L M}, X_{i t}^{F}, Z_{i t}$ and the error terms $u_{i t}$.

The random coefficients corresponding to individual and family background variables allow us to model the effects of these time-invariant personal characteristics on labor market and fertility decisions. The individual-specific random coefficients describe the individual-level heterogeneity in labor market and fertility behavior. The random coefficients corresponding to the constant terms in the four equations capture the variation in propensities for market work and children. The random coefficients corresponding to the children variables in the participation equations describe the heterogeneity of the effects of children on the level of labor market involvement, while those corresponding to the children variables in the fertility equation capture individual variation in the timing and spacing of births (for example, a relatively small individual-specific coefficient for the variables describing the presence of young children and a relatively large individual-specific coefficient for the variable describing the presence of older children indicates the occurrence of births at larger intervals). Finally, the general correlation structure of the random coefficients captures the correlation between preferences for market work and children, effects of children on labor supply, and fertility behavior-the number, and the timing and spacing of births. ${ }^{9}$

We assume error terms are jointly normally distributed, $u_{i t}=\left[u_{i t}^{1}\left|u_{i t}^{2}\right| u_{i t}^{3} \mid u_{i t}^{F}\right]^{\prime} \sim N(0, \Sigma)$.Over time, error terms follow a $\operatorname{AR}(1)$ stationary process, $u_{i t}=R u_{i t-1}+\varepsilon_{i t}$, where $\varepsilon_{i t}=\left[\varepsilon_{i t}^{1}\left|\varepsilon_{i t}^{2}\right| \varepsilon_{i t}^{3} \mid \varepsilon_{i t}^{F}\right]^{\prime}$ is distributed $\operatorname{IIDN}(0, \Psi), \Psi=I_{4}$, and it is uncorrelated with the random coefficients $\theta_{s k}$ and variables $X_{i t}^{L M}, X_{i t}^{F}, Z_{i t}$, and $R$ is a $4 \times 4$ diagonal matrix whose elements are the $\operatorname{AR}(1)$ coefficients corresponding to the four equations, $\rho_{1}, \rho_{2}, \rho_{3}$, and $\rho_{F} \cdot{ }^{10}$

\footnotetext{
${ }^{9}$ For each source of heterogeneity, random coefficients are assumed to be correlated within and between equations.

${ }^{10}$ The dynamic specification of both participation and fertility decisions requires assumptions regarding initial conditions. Specifically, we need to account for the distribution of the error terms and for the distributions of the children variables in the initial period. We assume that error terms follow stationary AR(1) processes, and we treat pre-sample error terms as parameters of the model. The selection of the sample ensures the number of children in the
} 
Work experience, while not explicitly included in the specification of labor market decisions, enters our model in two ways. First, since we explicitly model dependence of sequential labor market decisions, the level of labor market involvement in the previous periods directly affects current decisions. Second, current labor market decisions depend on potential wages in each labor market state, which, in turn, depend on labor market experience-the realization of past labor market decisions.

We exploit several sources of identification. First, we assume that the vectors of random coefficients corresponding to each source of heterogeneity have a joint normal distribution. Second, children variables entering the participation equations are non-linear transformations of the lagged dependent variables in the fertility equation. This non-linearity is generated by the way in which we construct the number the children variables-number of children in certain age categories-as well as by measuring fertility as the date of conception (the decision to conceive a child in a given year could result in the birth of a child in the same calendar year or in the following calendar year, as well as in the birth of twins).

Finally, we include the number of siblings with children in the fertility equation but not in the labor market equations. This exclusion restriction helps identify the model. Our use of this variable rests on significant evidence from demographic literature that siblings' fertility behavior affects fertility decisions through social interaction occurring in the context of interpersonal networks. ${ }^{11}$ In a panel data setting, identification comes from changes in the number of siblings with children. The temporal structure of the decision process we assume in this paper makes it unlikely that changes in the number of siblings with children are correlated with the error terms in the participation equations. While respondent's fertility variable captures the conception of a child during the current year, the number of siblings with children refers to the situation at the beginning of the same calendar year (children born to siblings during the past calendar year) and, therefore, reflects past fertility decisions made by the siblings. Even if contemporaneous shocks to labor supply are correlated across siblings, the number of siblings with children is predetermined. Evidence that changes in the number of siblings with children do impact a women's fertility decision is provided in Appendix table 1. In this table we present the estimation results of three OLS regressions where the number of children born between 1979 and 2003 is the dependent variable and the change in the number of siblings with children during the same period along with the number of siblings, respondent's education and race, respondent's parents' education are independent variables. The coefficient on the change in the number of siblings with children is significant in all specifications. In the specification that includes all controls, the coefficient for the change in the number of siblings with children is $0.1 .^{12}$

\footnotetext{
initial period is identical across individuals - we choose the first year out of school as the first period in the sample and we include only women who marry and have children only after entering our sample.

${ }^{11}$ Montgomery and Casterline (1996) provide a theoretical framework in which siblings' fertility affect fertility decisions through social interaction. Numerous papers provide empirical evidence that siblings' behavior influences a wide range of indices of fertility behavior: Rowe et al. (1989), Rodgers and Rowe (1988), Haurin and Mott (1990), Axinn, Clarkberg, and Thornton (1994).

${ }^{12}$ By comparison, Rosenzweig and Wolpin (1980), who use twins at the first birth as instrument for fertility, find that among women who have the first birth between 15 and 24, completed fertility, as measured 20 years later, was 0.15 greater for those women who had twins than for those women without twins. Angrist and Evans (1998) who use the gender of the first two children as instrument for the birth of the third child find that among parents with 2 or more children, the proportion that have the 3 child is 0.06 greater if the first two children were of the same sex than if they were of opposite sex.
} 


\subsection{Estimation}

To estimate the model, we employ Markov chain Monte Carlo techniques (MCMC). MCMC methods avoid one of the major difficulties inherent in the alternative maximum likelihood or simulated maximum likelihood estimation methods - the evaluation at each step of the maximization process of multiple integrals, whose dimensions increase very quickly with the number of equations to be estimated. The estimation algorithm we propose in this paper builds on several sources in the literature: Geweke et al. (1997) who propose a Gibbs sampler algorithm for estimating a panel multinomial probit model where errors follow an AR(1) process, McCulloch and Rossi (1994) who estimate a multi-period multinomial probit model with random effects, and Gilks et al. (1993) who propose an algorithm for the estimation of a single-equation, panel-data model with random coefficients.

The posterior kernel for our model is given by the product of a multivariate normal kernel, the kernel of the unconditional distribution of the pre-sample error terms, the prior distributions of the parameters, and an indicator function controlling the ordering and the signs of the latent variables. For the parameters of interest we choose proper but noninformative prior distributions. A sevenstep Gibbs sampling algorithm is employed to construct draws from the posterior distribution of the parameters. Convergence is assessed using the method proposed by Brooks and Gelman (1998).

The goal of the econometric model we propose is to examine the interaction between race/ethnicity, education, and fertility as determinants of women's life-time labor supply. Although the estimates for the global parameters of the model (posterior means and posterior standard deviations are showed in appendix table 2) and for the random coefficients (posterior means of the random coefficients corresponding to the interaction between race and education are showed in appendix table 3) provide interesting insights, they are difficult to interpret directly because of the non-linearity of the model. Therefore, we use simulations based on the estimation results.

\subsection{Simulation Design}

We confine our analysis to a period of 20 years following entry into the labor market, and we focus on fertility histories with no birth, one birth, and two births. For all fertility histories marriage takes place in the second year. The timing of the first birth varies between year 3 , the year following marriage, and year 20. For each possible timing of the first birth, the second birth can take place any period between the first birth and year 20 . The total number of fertility histories constructed in this way is 172 .

We construct nine individual profiles corresponding to the nine categories of the interaction between race and education: white woman with 12 years of education, black woman with 12 years of education, Hispanic woman with 12 years of education, white woman with 14 years of education, black woman with 14 years of education, Hispanic woman with 14 years of education, white woman with 16 years of education, black woman with 16 years of education, and Hispanic woman with 16 years of education. For all the profiles, personal characteristics are set at the values with the highest frequencies in our sample. We assume that none of the respondent's parents has college education and that respondent's mother did not work full time. We set other family income at zero, the region of residence to North-East, and the type of residence to urban. We set spouse's wage at 15530, the median level. For each individual profile, we set the random coefficients corresponding to the individual heterogeneity to zero, the average value. For every period along each possible labor market history, we compute the wages corresponding to the three working labor market states using 
the coefficient estimates from the wage equation, the characteristics associated with the relevant individual profile, and the labor market experience accumulated until that point in time.

For all individual profiles we compute the joint probability distribution of all possible labor market and fertility histories, $f\left(s_{1}, s_{2}, \ldots, s_{20}, h_{b_{1}, b_{2}}^{j}\right) . s_{t}$ denotes the labor market state in period $t, t=1, \ldots, 20 ; h_{b_{1}, b_{2}}^{j}$ denotes the fertility history corresponding to $j$ births, $j=0,1,2$, with first birth taking place in year $b_{1}$ and second birth taking place in year $b_{2}$, where $b_{1}$ and $b_{2}$ take value 0 if the corresponding birth does not take place. We then compute the probability of each fertility history, $f\left(h_{b_{1}, b_{2}}^{j}\right)$, along with the probability of all possible labor market histories conditional on the specific fertility history, $f\left(s_{1}, s_{2}, \ldots, s_{20} \mid h_{b_{1}, b_{2}}^{j}\right)$. Finally, we compute the probability distribution of the labor market states in every time period conditional on a given fertility history, $f\left(s_{t} \mid h_{b_{1}, b_{2}}^{j}\right)$.

We measure the effect of the first birth on the level of labor market involvement by comparing the probability distributions of the labor market states, $f\left(s_{t} \mid h_{b_{1}, b_{2}}^{j}\right)$, for the fertility histories with one birth with the fertility history with zero births, in the years following the birth:

$$
T E_{b_{1}}^{1}(t)=f\left(s_{t} \mid h_{b_{1}, 0}^{1}\right)-f\left(s_{t} \mid h_{0,0}^{0}\right), t \geq b_{1}
$$

The effect of the second birth is computed by comparing the probability distributions for the fertility histories with two births with the corresponding fertility history with one birth, in the years following the second birth:

$$
T E_{b_{1}, b_{2}}^{2}(t)=f\left(s_{t} \mid h_{b_{1}, b_{2}}^{2}\right)-f\left(s_{t} \mid h_{b_{1}, 0}^{1}\right), t \geq b_{2}
$$

We assess the role of the timing of the first birth by comparing the level of labor market involvement before the birth of the first child, $f\left(s_{b_{1}-1} \mid h_{0,0}^{0}\right)$, and the effect of the first child, $T E_{b_{1}}^{1}(t)$, for different timing of the first birth, $b_{1}=3, \ldots 20$. To assess the role of the spacing of the two births, we compare the effect of the second child, $T E_{b_{1}, b_{2}}^{2}(t)$, for different timing of the second birth, $b_{2}=b_{1}, \ldots 20$, assuming that the first birth takes place in year $3, b_{1}=3$, the year following marriage, which is the timing of the first birth with the highest frequency in the data.

We assess the differences across race/ethnicity and the way in which education influences these differentials by comparing results across the nine individual profiles corresponding to the interaction between race/ethnicity and education.

\section{Results}

We begin the presentation of the simulation results with an analysis of racial/ethnic differences with respect to three components of fertility decisions-completed fertility, the timing of the first birth, and the spacing of two births. Then we focus on the connection between fertility and the dynamics of the level of labor market involvement. We study the level of labor market involvement before the birth of the first child, $f\left(s_{b_{1}-1} \mid h_{0,0}^{0}\right)$, the effect of the first child on the level of labor market involvement, $T E_{b_{1}}^{1}(t)$, and the effect of the second child on the level of labor market involvement, $T E_{b_{1}, b_{2}}^{2}(t)$. We compare each one of these three measures of labor market dynamics across race/ethnicity, and we study the ways in which education influences racial/ethnic differences in the connection between fertility and labor market dynamics. 


\subsection{Completed fertility, the timing of the first birth, and the spacing of two births}

Figure 2 compares the predicted probability distributions for the number of children (panel A), timing of the first birth (panel B), and spacing of two births (panel C) of white, black, and Hispanic women, by level of education. ${ }^{13}$ Among women with 12 years of education, Hispanic women have more children than both white and black women. The probability of having no children is 0.067 for Hispanic women compared with 0.158 for black women and 0.178 for white women. The probability of having three or more children is 0.233 for Hispanic women compared with 0.136 for black women and 0.127 for white women. White women have fewer children than black women, although the differences between them are much smaller. Racial differences in completed fertility decline with the level of education. Even though Hispanic women remain likely to have more children, among women with 16 years of education the differences between the distributions are much smaller. The probability of having no children is 0.199 for Hispanic women, compared with 0.205 for black women and 0.212 for white women. The probability of having three or more children is 0.116 for Hispanic women, and 0.111 for both white and black women.

Among women with 12 years of education, white women are more likely to postpone the first birth than both black and Hispanic women. The probability of having the first child in the year following marriage is 2.8 percent higher for black women and 25.8 percent higher for Hispanic women. White women have relatively lower probabilities of having the first child in the first 7 years following marriage and relatively larger probabilities of having the first child 8 years or longer after marriage. Again, the difference between white and black women is much smaller than the differences between both white and black women and Hispanic women. As it was the case with completed fertility, race differences in the timing of the first birth vanish with the level of education. Among women with 16 years of education the timing of the first birth is very similar for white, black, and Hispanic women.

Among women with 12 years of education, white women are more likely to have the second birth in a time interval of two to five years after the birth of the first child. The probabilities are less concentrated for black and Hispanic women, who are relatively more likely to have the second birth in the year following the first birth or at an interval longer than 5 years. The comparison across levels of education shows that differences in the spacing of two births are also much smaller among women with higher education.

These results suggest that there are substantial differences among fertility decisions of white, black, and Hispanic women. White women have fewer children and are more likely to postpone the first birth and to have the second birth in the interval between 2 and 5 years after the first birth. These differences decline with the level of education to the point that among women with college education completed fertility, timing of the first birth and spacing of two births of white, black, and Hispanic women are virtually indistinguishable.

\subsection{The level of labor market involvement before the first birth}

Table 3 compares the level of labor market involvement before the birth of the first child, by education and race. Columns 1-3 of panel A compare the pre-birth levels of labor market involvement of white, black, and Hispanic women with 12 years of education, assuming the first birth takes

\footnotetext{
${ }^{13}$ In panels B and C, the probability profiles for white women have been normalized. Therefore, the profiles for the other categories show their probabilities relative to the corresponding probability for white women.
} 
place in the year following marriage. White women work more before the birth of the first child. Participation probability is 0.921 for white women compared with 0.874 for black women and 0.879 for Hispanic women. White women who participate have also higher levels of labor market involvement than black and Hispanic participants. The probability of working full time is 0.586 for white women (63.7 percent of those who participate) compared with 0.474 for black women (54.2 percent of those who participate) and 0.386 for Hispanic women ( 43.9 of those who participate). Black and Hispanic women, on the other hand, are more likely to work full time part year and part time. Probability of working full time part year is 0.196 for white women, 0.234 for black women, and 0.306 for Hispanic women, while the probability of working part time is 0.139 for white women, 0.167 for black women, and 0.187 for Hispanic women.

The comparison of results in columns 1-3 of panels A, B, and C shows that for all races, the level of labor market involvement increases with education. For white women, for example, participation increases from 0.921 , for women with 12 years of education, to 0.960 , for women with 14 years of education, and to 0.975 , for women with 16 years of education. At the same time the probability of working full time increases, while the probability of working full time part year and part time decline. This shift towards higher participation and higher probability of working full time is more pronounced for black and especially for Hispanic women. The 12-16 educational difference in participation is 0.054 for white women (the probability of participation of women with 16 years of education is larger than that of women with 12 years of education by 0.054), compared with 0.090 for black women and 0.088 for Hispanic women, and the educational difference in the probability of working full time is 0.158 for white women, compared with 0.169 for black women and 0.273 for Hispanic women. As a result, the race gap in the level of labor market involvement before the first birth declines with education. Even so, the disparities remain considerable even among women with higher education, especially with respect to the level of labor market involvement of participants, as white women are relatively more likely to work full time and less likely to work full time part year or part time.

To assess the effect of timing of the first birth, we show how $f\left(s_{b_{1}-1} \mid h_{0,0}^{0}\right)$ changes if the first birth takes place seven years after marriage, $b_{1}=9$, instead of the year following marriage, $b_{1}=3$. Columns 4-9 in panel A, which show the effect of the timing of the first birth for women with 12 years of education, indicate that for all races, delaying the first birth leads to higher prenatal levels of labor market involvement. Postponing the first birth by 6 years increases participation by 0.053 for white women, by 0.078 for black women, and by 0.076 for Hispanic women, increases the probability of working full time by 0.019 for white women, by 0.035 for black women, and by 0.028 for Hispanic women. The probabilities of working full time part year and part time also increase, and changes are larger for black and Hispanic women. Results in columns 4-9 of panels B and C show that for women with higher education the timing of the first birth has much smaller effects on the pre-birth level of labor market involvement and that these effects are very similar across races. The differences in the timing of the first birth (among women with 12 years of education, white women are more likely to postpone first birth, but race differentials vanish for higher levels of education) and the effect of postponing the first birth suggest that without controlling for the timing of the first birth the racial convergence in the pre-birth level of labor market involvement with education would appear stronger. 


\subsection{The effect of children on the level of labor market involvement}

We begin by focusing on white women with 12 years of education. For these women, we present the effects of two children on their level of labor market involvement, $T E_{b_{1}}^{1}(t), t \geq b_{1}$ and $T E_{b_{1}, b_{2}}^{2}(t), t \geq$ $b_{2}$. We assume the first birth takes place in year $3, b_{1}=3$, the year following marriage, and the second birth takes place in year $5, b_{2}=5$, two years after the first birth. This fertility history has the highest frequency in the data: most first births (23 percent) take place in the year following marriage, while most second births (30 percent) take place two years after the first birth. Next, using white women with 12 years of education as reference, we study the way in which the effect of each child varies across education and race/ethnicity. Finally, we focus on the effects of each child in the year of the birth, $T E_{b_{1}}^{1}\left(b_{1}\right), T E_{b_{1}, b_{2}}^{2}\left(b_{2}\right), b_{1}=3, b_{2}=5$ and study the connection between the timing of the first birth and the effect of the first child on the level of labor market involvement and between the spacing of two births and the effect of the second child on the level of labor market involvement.

Figure 3 shows the effects of two children on the level of labor market involvement for white women with 12 years of education. The birth of the first child reduces both participation and the level of labor market involvement of those who continue to work. The effect is strongest in the year of birth: participation probability falls by -0.256 , the probability of working full time falls by -0.274 , the probability of working full time part year falls by -0.079 percent, while the probability of working part time increases by 0.097 percentage points. The effect of the first child diminishes as the child grows older, but remains significant long after birth. Five years after birth, when the child moves into the age category 5 years or older, the probability of participation is 7.3 percentage points lower, the probability of working full time is 10 percentage points lower, the probability of working full time part year is 6.2 percentage points lower, while the probability of working part time is 8.9 percentage points higher. The second child reduces the level of labor market involvement the same way as the first child: participation and the probabilities of working full time and full time part year decline, while the probability of working part time increases. In the year of the second birth, participation declines by 0.279 , the probability of working full time declines by 0.224 , the probability of working full time part year declines by -0.085 , while the probability of working part time increases by 0.030 . The effect of the second child declines with the age of the child. Eight years after marriage, when the second child moves into age category 5 years and older, the second child reduces participation by 0.117 , the probability of working full time by 0.135 , the probability of working full time part year by 0.069 , and increases the probability of working part time by 0.088 .

Table 4 compares the effect of the first child across education and race/ethnicity. Columns 1-3 of panel A compare the effect of the first child in the year of birth, $T E_{b_{1}}^{1}\left(b_{1}\right)$, for white, black, and Hispanic women with 12 years of education. The effect of the first child is largest for white women and smallest for Hispanic women. The birth of the first child reduces participation by 0.256 for white women, by 0.177 for black women and by 0.134 for Hispanic women and the probability of working full time by 0.274 for white women, by 0.143 for black women and by 0.075 for Hispanic women. The probability of working full time part year decreases by 0.079 for white women, by 0.069 for black women, and by 0.051 for Hispanic women. The probability of working part time increases for white and black women and remains virtually unchanged for Hispanic women.

The comparison of results in columns 1-3 of panels A, B, and C shows that for all races the effect of the first child in the year of birth increases with education. Changes with the level of education are most pronounced for the negative effect of the first child on the probability of working full time and for the positive effect on the probability of working part time. This suggests that, as the level of education increases, women are more likely to work full time before the first birth and 
increasingly respond to the birth by moving from full time to part time jobs, rather than by stopping work altogether. The increase in the effect of the first child is largest for Hispanic women. Among Hispanic women, the 12-16 educational difference in participation is 0.071 (the negative effect of the first child on participation for women with 16 years of education is larger than that of women with 12 years of education by 0.071 ), compared with 0.007 for white women and -0.006 for black women. The educational difference in the effect of the first child on the probability of working full time is 0.195 for Hispanic women, compared with 0.076 for white women and 0.081 for black women. The educational difference in the positive effect of the first child on the probability of working part time are also larger for Hispanic women, for whom the effect increases by 0.136 compared with 0.047 for white women and 0.070 for black women. The differences among the effects of the first child for black and Hispanic women and that for white women decline with the level of education. The convergence is strongest for Hispanic women who experience strongest growth in both the pre-birth level of labor market involvement and the effect of the first child. For both black and Hispanic women, much of the gap disappears after two years of post-high school education.

Columns 4-9 show the effect of the first child 2 years after birth, $T E_{b_{1}}^{1}\left(b_{1}+2\right)$, when the child moves into age category $2-4$, and 5 years after birth, $T E_{b_{1}}^{1}\left(b_{1}+5\right)$, when the child moves in the age category 5 years and older. The effect of the first child declines with the age of the child for all levels of education and racial/ethnic groups. The differences across levels of education and race/ethnicity persist as the child grows older. The comparison of the black-white and Hispanic-white differentials across the age of the first child reveals, however, that black and Hispanic women return to work sooner after the first birth. For example, among women with 12 years of education, the black-white differential in the effect of the first child on the probability of working full time is 0.131 in the year of birth (the negative effect is smaller for black women), it increases to 0.206 when the child moves in age category 2-4, and returns to 0.143 when the child is 5 years old. This pattern holds with respect to both participation and full time work, for both black and Hispanic women. In addition, for both black and Hispanic women with 12 years of education, a five-year old child increases the probability of working full time.

Table 5 compares the effect of the second child across education and race/ethnicity. The results are to a large extent similar to those for the first child. The effect of the second child in the year of birth is stronger for white women compared to black and Hispanic women (columns 1-3). The effect increases with education. The growth is stronger for black and Hispanic women and, as a result, the differences among the effects of the second child for black and Hispanic women and the effect for white women decline with the level of education. The convergence is strongest for Hispanic women who experience strongest growth in the effect of the second child. For both black and Hispanic women, much of the gap vanishes in the transition between 12 years and 14 years of education. Columns 4-9 show that the effect declines with the age of the child for all levels of education and racial/ethnic groups. The decline is larger for black and Hispanic women, and as a result, the black-white and Hispanic-white differentials grow with the age of the child, for all levels of education.

We assess the way in which the timing of the first birth influences the effect of the first child on the level of labor market involvement by comparing the effect in the year of birth, $T E_{b_{1}}^{1}\left(b_{1}\right)$, for two alternative timings of the first birth: year $3, b_{1}=3$, the year following marriage, and year 9 , $b_{1}=9$, seven years after marriage (in this sample, 93 percent of the first births take place within seven years of marriage). We assess the way and the spacing of the two births influences the effect of the second child on labor supply by comparing the effect in the year of birth, $T E_{b_{1}, b_{2}}^{2}\left(b_{2}\right)$, for two alternative spacing of the two births: the second birth takes place two years and six years after 
the first birth, $b_{1}=3, b_{2}=5,9 .{ }^{14}$ The results are presented in table 6 . Columns 1-3 of panels A, B, and $\mathrm{C}$ show that postponing the first birth reduces the effect of the first child on the level of labor market involvement for all races and levels of education. All entries in columns 1-3 are positive, which indicates that the negative effects of the first child on participation and on the probabilities of working full time and full time part year decline in absolute value while the positive effect on the probability of working part time increases. The reductions are larger for women with higher levels of education. Among women with similar level of education reductions are larger for white women compared with both black and Hispanic women.

Columns 4-6 describe the way in which spacing of the two births influences the effect of the second child on the level of labor market involvement. For white women with all levels of education (column 4), having the second birth after a longer time interval reduces the negative effects of the second child on participation and on the probability of working full time part year, increases the negative effect on the probability of working full time and the positive effect of working part time. While it is easy to see that delaying the first birth reduces the effect of the first child on labor supply, it is much harder to assess whether the change in the effect of the second child on the distribution of the labor market states, with the spacing of the second birth, represents a decrease or an increase of this effect. We do so by mapping these changes into number of hours, assuming the number of hours associated with each labor market state is the respective average for this sample ( $2218 \mathrm{~h}$ for full time, $1030 \mathrm{~h}$ for full time part year, and $877 \mathrm{~h}$ for part time) and find that, for white women, delaying the second birth from year 5 to year 9 leads to a very small increases in the negative effect of the second child of $4 \mathrm{~h} .{ }^{15}$ The increase in the effect of the second child on the level of labor market involvement is larger for white women with higher education who experience larger increases in both the negative effect on the probability of working full time and the positive effect on the probability of working part time. Translated into hours, delaying the second birth from year 5 to year 9 increases the effect of the second child by $42 \mathrm{~h}$ for women with 14 years of education and by $63 \mathrm{~h}$ for women with 16 years of education. Having the second birth after a longer time interval leads to substantial reductions of the negative effects of the second child on the level of labor market involvement for black and Hispanic women who not only experience larger reductions in the effect of the second child on participation, but also reductions in the effect of the second child on the probability of working full time.

\subsection{The level of labor market involvement after the first and second births}

Table 7 shows the dynamics of the level of labor market involvement around the first birth for the fertility history with one child born in year 3, the year following marriage. A comparison of the results in panels $\mathrm{A}, \mathrm{B}$, and $\mathrm{C}$ shows that even though women with higher education face larger negative effects of children, the level of labor market involvement in the period following the first birth increases with education for all racial/ethnic groups. For all levels of education, Black and Hispanic women work less before the birth of the first child (columns 1-3), but they have higher levels of labor market involvement following the birth of the child (columns 4-12). Racial/ethnic

\footnotetext{
${ }^{14}$ We focus on the effects of children in the year of birth because the differences due to timing and spacing are strongest while the child is very young. As children grow older, their effects decline and so do the differentials due to the timing and spacing of the births - five years after birth these differences are negligible.

${ }^{15}$ The results did not change when we computed these effects using two alternative assumptions: the median number of hours for each labor market state; and $2000 \mathrm{~h}$ for full time, $1000 \mathrm{~h}$ for full time part year, and $1000 \mathrm{~h}$ for part time.
} 
differences are largest when the child is 3 years old (age category 2-4), which indicates that black and Hispanic women return to work faster than white women with similar levels of education. The level of labor market involvement increases with the age of the child. For all levels of education, when the first child is 5 years old (age category 5 years and older), black women have the highest level of labor market involvement-they are both more likely to participate and to work full time. Hispanic women with 12 years of education have lower levels of labor market involvement than white women with the same level of education, Hispanic women with 14 years of education work more than white women with 14 years of education, while among those with 16 years of education levels of labor market involvement are similar. Finally, black and Hispanic women with 12 years education work more five years after the first birth than before the first birth.

Table 8 shows the dynamics of the level of labor market involvement around the second birth for the fertility history with two children born in years 3 and 5 . For all levels of education, black and Hispanic women work more than white women after the birth of the second child (columns 4-12). The racial/ethnic differences are more pronounced than after the birth of the first child, and again, they are largest when the second child is 3 years old (age category 2-4), which indicates that black and Hispanic women return to work faster than white women with similar levels of education. The comparison across levels of education reveals a less clear pattern: among white women, the level of labor market involvement after the birth of the second child increases with education; among black women, those with 12 years of education have the highest level of labor market involvement followed by those with 16 years of education; among Hispanic women, those with 14 years of education have the highest level of labor market involvement. Five years after the birth of the second child (when the child moves into age category 5 years and older) black and Hispanic women with 12 years of education work more than they did before the birth of the first child.

\section{Summary and Discussion}

In this paper we analyze the differences in life-cycle labor supply among white, black, and Hispanic women, focusing on the interaction between race/ethnicity, education, and fertility. We jointly model labor market and fertility decisions using a mixed-effect simultaneous-equation framework. This empirical approach addresses three key issues in the estimation of the effects of children on labor supply: the endogeneity of labor market and fertility decisions; the heterogeneity of the effects of children on labor supply and their correlation with fertility decisions; and the correlation of sequential labor market decisions. We estimate our model using a 25-year panel, considerably longer than those previously used in the literature, which follows women from their entry into the labor force and captures almost complete fertility histories. The data drawn from the 1979 National Longitudinal Survey of Youth (NLSY79) includes women with ages between 14 and 21 years old in 1979, the generation that has driven the reversal and subsequent widening of the racial employment gap.

Our results show an intricate interaction between race/ethnicity, education, and fertility as determinants of women's life-cycle labor supply. Educational differences across race/ethnicity play an important role. White women have the highest levels of education and Hispanic women have the lowest levels of education, and other things equal, women with higher education have fewer children, have the first birth later in life, space subsequent births more closely together, work more before the birth of the first child, but face larger negative effects of children on their level of labor market involvement.

Controlling for education, we find substantial differences among the fertility decisions of white, 
black, and Hispanic women. Compared with black and Hispanic women, white women have fewer children, have the first birth later in life, and have the second birth after a shorter time interval. With respect to all three dimensions of the fertility decisions, black women are more similar to white women than Hispanic women. Racial/ethnic differences in fertility decisions decline with the level of education; they are largest among women with 12 years of education or less, while among women with college education, completed fertility, timing of the first birth and spacing of two births of white, black, and Hispanic women are virtually indistinguishable.

The level of labor market involvement before the birth of the first child is highest for white women and lowest for Hispanic women. It increases with education and, as the growth is stronger for black and especially for Hispanic women, the racial/ethnic differences decline with education.

The birth of a child reduces both participation and the level of labor market involvement of those who continue to work. The effect is largest for white women and smallest for Hispanic women. For all racial/ethnic groups the effect increases with the level of education. Much of the increase with education takes place in the transition between 12 years of education or less and 13-15 years of education and it is strongest for Hispanic women and weakest for white women. As a result, the gap between the labor supply responsiveness to children of white and Hispanic women clearly narrows with education. The gap between the labor supply responsiveness to children of white and black women declines in the transition between 12 years of education or less and 13-15 years, but increases again for women with 16 years of education.

Children reverse the relationship between race/ethnicity, education, and level of labor market involvement. Before the birth of the first child, women with higher education and, controlling for education, white women worked more. Children have larger, longer-term effects on white women and on women with higher education. As a result, black and Hispanic women with children work more than white women with children. When the second child is five years old, black and Hispanic women have higher participation and higher levels of labor market involvement among participants. The birth of the first child greatly reduces the employment gap across levels of education. Women with higher education, however, continue to work more. The birth of the second child, however, completely reverses the educational employment gap-women with lower education are more likely to participate and those who participate have higher levels of labor market involvement. Remarkably, black and Hispanic women with children have higher levels of labor market involvement than black and Hispanic women without children.

The timing and spacing of births are important determinants of the effect of children on women's labor supply, and their effects differ across race/ethnicity and education. Delaying the first birth leads to higher levels of labor market involvement before the birth of the first child and reduces the negative effect of the first child on the level of labor market involvement. The effect on the pre-natal level of labor market involvement is stronger for those who work less-women with lower education and among those with lower education for Hispanic women. On the other hand, the reductions in the negative effect of the first child are larger for those who face larger effects-women with higher education and, among women with similar level of education, for white women. Spacing the second birth increases the effect of the second child for white women but reduces it for black and Hispanic women.

In many respects our results are very similar to those of previous studies. The negative correlation between mother's education and number of children ever born is the strongest and most widely and frequently observed relationship in empirical studies of fertility (Michael, 1973, Heckman and Walker, 1990). Differences in the timing of the first birth across both education and race/ethnicity are also well documented: women with higher education are more likely to delay maternity (Cigno 
and Ermisch, 1989, Happel et al., 1984, and Gustafsson and Wetzels, 2000) and white women have shifted childbearing to later ages to a larger extent than non-white women (Hotz et al., 1997).

The increase in labor supply responsiveness to children with education is comparable with results of Gronau (1973), Hill and Stafford (1980), Leibowitz (1974), Mincer and Polacheck (1974, 1978), while the differences across race/ethnicity are similar to the results of Bell, 1974, Lehrer, 1992, Shapiro and Mott, 1994. These differences could be due to minority women having better access to informal child care. The similarity between the ways in which education and race affect the relationship between fertility and labor supply suggests, however, that differences across race and ethnicity could be in part generated by human capital differences: minorities are more likely to live in central city and racial and economic segregation in the housing market may affect quality of schooling leading to less human capital even for the same level of schooling (Aaronson, 1998, and Altonji and Blank, 1999). Both channels are consistent with our finding that differences in labor supply responsiveness decrease with education: the less local structure of the labor market for individuals with higher education implies that access to informal child care diminishes with education; the heterogeneity of school quality is also likely to decrease with the level of schooling. 


\section{Appendix.}

\subsection{Estimation algorithm}

To estimate the model, we employ Markov chain Monte Carlo techniques. Our approach combines elements from several sources in the literature. Geweke et al. (1997) propose a Gibbs sampler algorithm for estimating a panel MNP model where errors follow an AR(1) process. McCulloch and Rossi (1994) also use a Gibbs sampler to estimate a multiperiod multinomial probit model with random effects. The general random effects framework has been used for a long time in Bayesian hierarchical modeling of longitudinal data. In this paper we use the same approach as in Gilks et al. (1993). Also related, albeit in a continuous setting, is the paper by Chib and Greenberg (1995) on hierarchical SUR models with correlated errors. Finally, MCMC techniques for estimating multivariate probit models have been introduced by Chib and Greenberg (1998). We extend existing work by combining two discrete choice processes and jointly estimating the parameters of interest in both models.

The data set is an unbalanced panel, with $N$ individuals $i=1, . ., N$, each individual $i$ is observed for $T_{i}$ periods. The total number of observations is $d f=\sum_{i=1}^{N} T_{i}$. Let $W_{i t}^{L M}=\left[K_{i t} \mid X_{i t}^{L M}\right], W_{i t}^{F}=$ $\left[K_{i t} \mid X_{i t}^{F}\right]$, and define the block diagonal matrices

$$
\tilde{W}_{i t}=\left[\begin{array}{cccc}
W_{i t}^{L M} & 0 & 0 & 0 \\
0 & W_{i t}^{L M} & 0 & 0 \\
0 & 0 & W_{i t}^{L M} & 0 \\
0 & 0 & 0 & W_{i t}^{F}
\end{array}\right], \tilde{K}_{i t}=\left[\begin{array}{cccc}
K_{i t} & 0 & 0 & 0 \\
0 & K_{i t} & 0 & 0 \\
0 & 0 & K_{i t} & 0 \\
0 & 0 & 0 & K_{i t}
\end{array}\right]
$$

The conforming matrix of parameters is $\tilde{\beta}=\left[\alpha^{1 \prime}\left|\beta^{1 \prime}\right| \alpha^{2 \prime}\left|\beta^{2 \prime}\right| \alpha^{3 \prime}\left|\beta^{3 \prime}\right| \alpha^{F^{\prime}} \mid \beta^{F^{\prime}}\right]^{\prime}$. Define $U_{i t}=$ $\left[U_{i t}^{1}\left|U_{i t}^{2}\right| U_{i t}^{3} \mid U_{i t}^{F}\right]^{\prime}, \tilde{Z}_{i t}=\left[\left(Z_{i t}^{1} \mid\left(K_{i t} * Z_{i t}^{1}\right)\right)^{\prime}\left|\left(Z_{i t}^{2} \mid\left(K_{i t} * Z_{i t}^{2}\right)\right)^{\prime}\right|\left(Z_{i t}^{3} \mid\left(K_{i t} * Z_{i t}^{3}\right)\right)^{\prime} \mid 0\right]^{\prime}$. Let $\tilde{\gamma}=\left[\gamma \mid \delta^{\prime}\right]^{\prime}$ Using this notation the model becomes

$$
U_{i t}=\tilde{W}_{i t} \tilde{\beta}+\tilde{Z}_{i t} \tilde{\gamma}+\sum_{m} \tilde{K}_{i t} \theta_{m l(i, m)}+u_{i t}
$$

Define $U_{i 0}=u_{i 0}, \tilde{K}_{i 0}=[0], \tilde{W}_{i 0}=[0], \tilde{Z}_{i 0}=[0]$. Finally, let $\dot{U}_{i t}=U_{i t}-R U_{i t-1} ; \dot{\tilde{W}}_{i t}=$ $\tilde{W}_{i t}-R \tilde{W}_{i t-1} ; \dot{K}_{i t}=\tilde{K}_{i t}-R \tilde{K}_{i t-1} ; \tilde{Z}_{i t}=\tilde{Z}_{i t}-R \tilde{Z}_{i t-1}$.

To describe the sequence of labor market and fertility decisions, define $d_{i t}^{L M}=\left[d_{i t}^{1}, d_{i t}^{2}, d_{i t}^{3}, d_{i t}^{0}\right]=$ $\left[y_{i t}^{F T}, y_{i t}^{F P}, y_{i t}^{P T}, y_{i t}^{N W}\right], d_{i t}^{F}=y_{i t}^{F}, d_{i t}=\left[d_{i t}^{L M}, d_{i t}^{F}\right], d_{i}=\left[d_{i 1}, \ldots, d_{i T}\right]$.

The posterior kernel is given by the product of a multivariate normal kernel, the kernel of the unconditional distribution of the pre-sample error terms, the prior distributions of the parameters, and an indicator function controlling the ordering and the signs of the latent variables.

- The kernel of the joint normal distribution is:

$$
|\Psi|^{-\frac{d f}{2}} \exp \left\{-\frac{1}{2} \sum_{i=1}^{N} \sum_{t=1}^{T_{i}}\left(u_{i t}-R u_{i, t-1}\right)^{\prime} \Psi^{-1}\left(u_{i t}-R u_{i, t-1}\right)\right\}
$$

where $u_{i t}=U_{i t}-\tilde{W}_{i t} \tilde{\beta}-\tilde{Z}_{i t} \tilde{\gamma}-\sum_{m} \tilde{K}_{i t} \theta_{m i}$ 
- The kernel of the unconditional distribution of the pre-sample error:

$$
\left|V_{0}(R, \Psi)\right|^{-\frac{N}{2}} \exp \left\{-\frac{1}{2} \sum_{i=1}^{N} u_{i 0}^{\prime}\left[V_{0}(R, \Psi)\right]^{-1} u_{i 0}\right\}
$$

where $\left[V_{0}(R, \Psi)\right]_{j k}=\frac{\psi_{j k}}{\rho_{j} \rho_{k}}$

- The indicator function for consistency and signs of U's:

$$
\prod_{i=1}^{N} \prod_{t=1}^{T_{i}} H\left(U_{i t}, d_{i t}\right)
$$

- Prior distributions
a. $\beta_{j} \sim N\left(\beta_{j 0}, B_{j 0}\right), j \in(1,2,3, F)$
b. $\gamma \sim N\left(\gamma^{0}, \Gamma_{0}\right)$
c. $\rho_{j} \sim T N\left(\rho_{j}^{0}, \sigma_{\rho_{j}^{0}}\right), j \in(1,2,3, F)$
d. $D_{m}^{-1} \sim W\left(b_{m}, B_{m}\right)$

The prior distribution for $\tilde{\beta}$ is multivariate normal with mean 0 and a variance matrix of 100 times the identity matrix, the prior distribution for $\tilde{\gamma}$ is univariate normal with mean 0 and variance 100 , the prior distribution for $\rho$ is truncated normal with mean 0.5 and variance 0.25 , the prior distribution for the precision matrix $D_{m}^{-1}$ is Wishart with parameters $b_{m}=3, B_{m}=0.01 * I$, where $I$ is an identity matrix with appropriate dimension.

A seven-step Gibbs sampling algorithm is employed to construct draws from the posterior distribution.

- Step 1. Draw $U_{i t}\left(i=1, \ldots ., N, t=1, \ldots ., T_{i}\right)$

$$
\left[U_{i t} \mid \tilde{\beta}, \tilde{\gamma}, \theta_{s k(i, s)}, D_{s}, R, u_{i 0}\right] \text { is a truncated multivariate normal distribution with mean }\left[\begin{array}{c}
\mu_{i 1}+R u_{i 0} \\
\ldots \\
\mu_{i T}+R^{T} u_{i 0}
\end{array}\right]
$$

and variance $G\left(I_{T} \otimes \Psi\right) G^{\prime}$ where $\mu_{i t}=\tilde{W}_{i t} \tilde{\beta}+\tilde{Z}_{i t} \tilde{\gamma}+\sum_{s} \tilde{K}_{i t} \theta_{s k(i, s)}$ and

$$
G=\left[\begin{array}{cccccc}
I_{4} & 0 & 0 & \cdots & 0 & 0 \\
R & I_{4} & 0 & \cdots & 0 & 0 \\
\cdots & \ldots & \cdots & \cdots & \cdots & \cdots \\
R^{T-1} & R^{T-2} & R^{T-3} & & R & I_{4}
\end{array}\right]
$$

To draw from a truncated normal distribution, we used the method proposed by Geweke (1991).

- Step 2. Draw $u_{i 0}(i=1, \ldots ., N)$.

The conditional distribution $\left[u_{i 0} \mid U_{i t}, \tilde{\beta}, \tilde{\gamma}, \theta_{s k(i, s)}, D_{s}, R\right]$ is only a function of $u_{i 1}, R$, and $\Psi$.

$$
u_{i 0} \sim N\left[C u_{i 1}, V_{0}(R, \Psi)-C V_{0}(R, \Psi) C^{\prime}\right]
$$

where $C=\left[V_{0}(R, \Psi)\right] R\left[V_{0}(R, \Psi)\right]^{-1}$ 
- Step 3. Draw $\rho$. The conditional distribution distribution $\left[\rho \mid U_{i t}, \tilde{\beta}, \tilde{\gamma}, \theta_{s k(i, s)}, D_{s}, u_{i 0}\right]$ is

$$
N\left[H_{\rho}\left(\nu_{\rho}+V_{\rho}^{-1} \rho^{0}\right),\left(H_{\rho}+V_{\rho}^{-1}\right)^{-1}\right]
$$

truncated to the hypercube dictated by stationarity, where

$$
\left.\begin{array}{l}
H_{\rho}=\left[\begin{array}{cccc}
\psi^{11} \sum_{i=1}^{N} \sum_{t=1}^{T_{i}}\left(u_{i t-1}^{1}\right)^{2} & \ldots & \psi^{13} \sum_{i=1}^{N} \sum_{t=1}^{T_{i}} u_{i t-1}^{1} u_{i t-1}^{3} & \psi^{1 F} \sum_{i=1}^{N} \sum_{t=1}^{T_{i}} u_{i t-1}^{1} u_{i t-1}^{F} \\
\psi^{13} \sum_{i=1}^{N} \sum_{t=1}^{T_{i}} u_{i t-1}^{1} u_{i t-1}^{3} & \ldots & \psi^{33} \sum_{i=1}^{N} \sum_{t=1}^{T_{i}}\left(u_{i t-1}^{3}\right)^{2} & \psi^{3 F} \sum_{i=1}^{N} \sum_{t=1}^{T_{i}} u_{i t-1}^{3} u_{i t-1}^{F} \\
\psi^{F 1} \sum_{i=1}^{N} \sum_{t=1}^{T_{i}} u_{i t-1}^{F} u_{i t-1}^{1} & \psi^{F 3} \sum_{i=1}^{N} \sum_{t=1}^{T_{i}} u_{i t-1}^{F} u_{i t-1}^{3} & \psi^{F F} \sum_{i=1}^{N} \sum_{t=1}^{T_{i}}\left(u_{i t-1}^{F}\right)^{2}
\end{array}\right] \\
\nu_{\rho}=\left[\begin{array}{c}
\sum_{j} \psi^{1 j} \sum_{i=1}^{N} \sum_{t=1}^{T_{i}} u_{i t-1}^{1} u_{i t}^{j} \\
\sum_{j} \psi^{3 j} \sum_{i=1}^{N} \sum_{t=1}^{T_{i}} u_{i t-1}^{1} u_{i t}^{j} \\
\sum_{j} \psi^{F j} \sum_{i=1}^{N} \sum_{t=1}^{T_{i}} u_{i t-1}^{F} u_{i t}^{j}
\end{array}\right], V_{\rho}=\operatorname{diag}\left(\sigma_{\left.\rho_{1}^{0}, \sigma_{\rho_{1}^{0}}, \sigma_{\rho_{3}^{0}}, \sigma_{\rho_{F}^{0}}\right)}\right.
\end{array}\right]
$$

Due to the truncation, an acceptance step is necessary. Draws are rejected if $\left|\rho_{j}\right| \geq 1$ for any $j$, then accepted with probability

$$
\left|V_{0}(R, \Psi)\right|^{-\frac{N}{2}} \exp \left\{-\frac{1}{2} \operatorname{tr} S_{u_{0}} V_{0}(R, \Psi)^{-1}\right\} \div\left|\frac{1}{N} S_{u_{0}}\right|^{-\frac{N}{2}} \exp \left(-\frac{N L}{2}\right)
$$

where $S_{u_{0}}=\sum_{i=1}^{N} u_{i 0} u_{i 0}^{\prime}$

- Step 4. Draw $\tilde{\beta}_{j}, j=1,2,3, F$. Conditional distribution $\left[\tilde{\beta}_{j} \mid U_{i t}, \tilde{\gamma}, \theta_{s k(i, s)}, D_{s}, R, u_{i 0}\right]$ is a multivariate normal $\tilde{\beta}_{j} \sim N\left[b_{j}, B_{j}\right]$

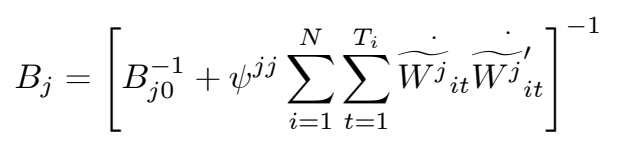

and mean

$$
b_{j}=B_{j}\left(B_{j 0}^{-1} \beta_{j 0}+\sum_{l} \psi^{j l} \sum_{i=1}^{N} \sum_{t=1}^{T_{i}} \stackrel{\dot{W^{j}}}{i t} w_{i t}^{l(j)^{\prime}}\right)
$$


where $w_{i t}^{l(j)}=\dot{U}_{i t}^{l}-\dot{\widetilde{W}}_{i t} \tilde{\beta}_{l}-\dot{\widetilde{Z}}_{i t} \tilde{\gamma}-\sum_{m} \tilde{K}_{i t} \delta_{m l(i, m)}$, for $l \neq j$ and $w_{i t}^{j(j)}=\dot{U}_{i t}^{j}-\tilde{Z}_{i t}^{j} \tilde{\gamma}-$ $\sum_{m} \tilde{K}_{i t} \theta_{m l(i, m)}$

- Step 5. Draw $\tilde{\gamma}$.Conditional distribution $\left[\tilde{\gamma} \mid U_{i t}, \tilde{\beta}, \theta_{s k(i, s)}, D_{s}, R, u_{i 0}\right]$ is normal $\gamma \sim N[g, \Gamma]$ where the variance is

$$
\Gamma=\left[\Gamma_{0}^{-1}+\sum_{i=1}^{N} \sum_{t=1}^{T_{i}} \sum_{l} \sum_{j} \psi^{j l} \dot{Z}_{i t}^{j} \dot{Z}_{i t}^{l \prime}\right]^{-1}
$$

and the mean is

$$
g=\Gamma\left(\Gamma_{0}^{-1} \tilde{\gamma}_{0}+\sum_{i=1}^{N} \sum_{t=1}^{T_{i}} \sum_{l} \sum_{j} \psi^{j l} \dot{Z}_{i t}^{j}\left(\dot{U_{i t}^{l}}-\dot{\tilde{W}}_{i t}^{l} \widetilde{\beta}_{l}-\sum_{m} K_{i t} \theta_{m l(i, m)}^{l}\right)\right)
$$

where $j, l=1,2,3, F$.

- Step 6. Draw $\theta_{m l}$ for each source of heterogeneity. Conditional distributions $\left[\theta_{m l} \mid U_{i t}, \tilde{\beta}, \tilde{\gamma}, D_{s}, R, u_{i 0}\right]$ are multivariate normal

$$
\left[\theta_{m l} \mid \cdot\right]=N\left(D_{m} \sum_{i: l(i, m)=k} \sum_{t=1}^{T} \tilde{K}_{i t} \Psi^{-1} e_{m i t}, D_{m}\right)
$$

where

$D_{m}=\left[\Omega_{m}^{-1}+\sum_{i: l(i, m)=k} \sum_{t=1}^{T} \tilde{K}_{i t} \Psi^{-1} \tilde{K}_{i t}^{\prime}\right]^{-1}$

and

$e_{m i t}=U_{i t}-\tilde{W}_{i t} \tilde{\beta}-\tilde{Z}_{i t} \tilde{\gamma}-\sum_{g: g \neq m} \tilde{K}_{i t} \theta_{g l(i, g)}$. Here, $\sum_{i: l(i, m)=k}$ means sum for all individuals

observations $i$ for whom factor $m$ is at level $k$ and $\sum_{g: g \neq m}$ means sum for all factors except $m$.

- Step 7. Draw $D_{m}^{-1}$ for each source of heterogeneity. Conditional distributions $\left[D_{m}^{-1} \mid U_{i t}, \tilde{\beta}, \tilde{\gamma}, \theta_{m l}, R, u_{i 0}\right]$ are Wishart.

$$
D_{m}^{-1} \sim W\left(b_{m}+k_{m}, B_{m}+\sum_{l=1}^{l_{m}} \theta_{m l} \theta_{m l}^{\prime}\right)
$$

Convergence is assessed using the method proposed by Gelman and Rubin (1992) with the modified correction factor proposed by Brooks and Gelman (1998). One preliminary run of 14000 iterations, with OLS coefficients as starting values, was used to construct starting values for four independent chains. The starting values were extreme values chosen from the posterior distribution of the coefficients. The four independent chains, each with 15000 iterations were used to compute the scale reduction factor. Appendix Table 2 shows the scale reduction factors for the slope coefficients, and for the $\operatorname{AR}(1)$ coefficients. 


\subsection{Data Appendix}

Due to problems with the data we needed to impute some of the data values. The three main problems we faced were, top-coding of income, missing values for wages and income, and missing values for hours worked. Here we will briefly outline how we addresses each problem

\subsubsection{Top-Coding of Spouse's Wage, Income from Business and Other Income}

The top-coding of income data in the NLSY varies by year. From 1979 to 1984 all income values above $\$ 75,000$ were truncated to $\$ 75,001$. From 1985 to 1900 all income values greater than $\$ 100,000$ were truncated to $\$ 100,001$. Since this method produced a downward bias in the mean value of income, starting in 1989 all values above the cutoff value were replaced with the average of the true values of income above this level. For our analysis the method used in the later period is acceptable, where as the method used in the earlier period two periods should not result in a bias in our parameter estimates. To adjust the top-coded values in the early years so that they match the values in the latter years we first compute the mean income for the top ten percent of non-top coded values in all years of the data. We then compute the average of the ratio of the top coded values with the mean of the top ten percent of the non-top coded values, across all of the latter years of the data (1989-2004). We multiplied this ratio by the mean of the top ten percent of the non-top coded values in the early years of the data (1979-1984). Finally we replaced the top coded values in the early years with this new value.

\subsubsection{Imputing Missing Wages and Income}

Once we fixed the top coding problem we then imputed missing wages and income for all individuals in our sample. For individuals who had more than three observations we regressed either log wages or log income on a constant and a time trend and used the results from this regression to impute the missing data. If only one or two values were available, we imputed the missing values with the mean deflated value of the wage or income. After 1994, NLSY74 was conducted every other year. We impute the values for the missing post-1994 years by interpolating the deflated values of the wage or income of adjacent years.

\subsubsection{Imputing Missing Hours Worked}

The NLSY collects information on hours worked each week for every week in the survey. We aggregate these weekly hours worked into hours worked in each year for individuals in our sample. If someone has a missing or invalid value for hours worked in a week we impute the value for that week by taking a weighted mean over all valid values of weekly hours worked in the survey. The weight we use is $0.5 / m$ where $m$ is the difference between the current week and the week of the valid observation. 


\section{References}

Aaronson, D. (1998), "Using Sibling Data to Estimate the Impact of Neighborhoods on Children's Educational Outcomes," Journal of Human Resources, 33, 915-946.

Altonji, J. G. and Blank, R. M., (1999) "Race and Gender in the Labor Market," in Handbook of Labor Economics, eds. O. Ashenfelter and D. Card, North-Holland, Amsterdam, 3143-3259.

Angrist, J. D., and Evans, W. N. (1998), "Children and Their Parents' Labor Supply: Evidence from Exogenous Variation is Family Size," The American Economic Review, 80, 450-477.

Axinn, W. G., Clarkberg, M. E. and Thornton, A. (1994), "Family Influences on Family Size Preferences," Demography, 31, 65-79.

Becker, G. (1965), "A Theory of the Allocation of Time," Economic Journal 75, 493-517.

Bell, D., (1974), "Why Participation Rates of Black and White Wives Differ, " Journal of Human Resources, 9, 465-479.

Björklund, A. and Moffitt, R. (1987), "The Estimation of Wage and Welfare Gains in Self-Selection Models." Review of Economics and Statistics 69, 42-49.

Blau, F. D. (1998), "Trends in the Well-Being of American Women (1970-1995)," Journal of Economic Literature, 36, 112-165.

Blau, F. D., Ferber, M. A., and Winkler, A. E. (1998), "The Economics of Women, Men, and Work," Prentice Hall, Englewood Cliffs, New Jersey.

Browne, I. (1997) "Explaining the Black-White Gap in Labor Force Participation among Women Heading Households," American Sociological Review, 62, 236-252.

Bowen, W. G. and Finegan, T. A. (1969), The Economics of Labor Force Participa- tion. Princeton, N.J.: Princeton University Press, 1969.

Brooks, S. P., and Gelman, A. (1998), "General Methods for Monitoring Convergence of Iterative Simulations," Journal of Computational and Graphical Statistics, 7, 434-455.

Cain, G. G. (1966). Married Women in the Labor Force: An Economic Analysis. Chicago: University of Chicago Press.

Carneiro, P., Heckman, J., and Vytlacil, E. (2001), "Estimating the Rate of Return to Schooling when It Varies among Individuals," Economic Journal Lecture, Royal Economic Society.

Carrasco, R. (2001), "Binary Choice with Binary Endogenous Regressors in Panel Data: Estimating the Effect of Fertility on Female Labor Force Participation," Journal of Business and Economic Statistics, 19, 385-394.

Cigno, A. (1991), Economics of the Family. Clarendon Press, Oxford.

Cigno, A. and Ermisch, J. (1989), "A Microeconomic Analysis of the Timing of Births," European Economic Review 33, 737-760. 
Cohen, Philip N., and Bianchi, Suzanne M. (1999) "Marriage, children, and women's employment: What do we know?" Monthly Labor Review 122, 22-3 1.

Corcoran, M. (1999) "Black women's economic progress." In Race, Gender and Economic Inequality: African-American and Latina Women in the Labor Market, ed Browne, I., Russell Sage, New York.

England, P., Garcia-Beaulieu, C., Ross, M. (2004) "Women's Employment among Blacks, Whites, and Three Groups of Latinas: Do More Privileged Women Have Higher Employment?" Gender and Society, Vol. 18, ), 494-509.

Geweke, J., Keane, M. P., and Runkle, D. E. (1997), "Statistical Inference in the Multinomial Multiperiod Probit Model," Journal of Econometrics, 80, 125-165.

Gilks, W. R., Wang, C. C., Yvonnet B., and Coursaget, P. (1993), "Random-Effects Models for Longitudinal Data Using Gibbs Sampling," Biometrica, 49, 441-453.

Goldin, C. (1990), Understanding the Gender Gap: An Economic History of American Women. New York, Oxford University Press.

Gronau, R. (1977), "Leisure, Home Production, and Work - the Theory of the Allocation of Time Revisited," Journal of Political Economy, 85, 1099-1123.

Gustafsson, S. (2001), "Optimal Age at Motherhood. Theoretical and Empirical Considerations on Postponement of Maternity in Europe," Journal of Population Economics 14, 225-247.

Gustafsson, S. and Wetzels, C. (1997), "Paid Careers and the Timing and Spacing of Births in Germany, Great Britain and Sweden'" in Time Allocations and Gender. The relationship Beteween Paid Labour and Household Work, eds Tijdens K, Doorne-Huiskes A, van, Willemsen T., Tilburg University Press, Tilburg.

Gustafsson, S. and Wetzels, C. (2000), "Optimal Age at Giving Birth: Germany, Great Britain, the Netherlands and Sweden," in Gender and the Labour Market. Econometric Evidence on Obstacles in Achieving Gender Equality, eds Gustafsson S., Meulders, D., MacMillan, London.

Happel, S., Hill, J., and Low, S. (1984), "An Economic Analysis of the Timing of Childbirth", Population Studies 38: 299-311.

Haurin, R. J, and Mott, F. L. (1990), "Adolescent Sexual Activity in the Family Context: The Impact of Older Siblings," Demography, 27, 537-557.

Heckman, J. and Robb, R. (1985), "Alternative Methods for Evaluating the Impact of Interventions," in Longitudinal Analysis of Labor Market Data, eds J. Heckman and B. Singer. Cambridge University Press.

Heckman, J. and Vytlacil, E. (1999), "Local Instrumental Variables and Latent Variable Models for Identifying and Bounding Treatment Effects," Proceedings of the National Academy of Sciences, 96 (April). 4730-4734.

Heckman, J. and Vytlacil, E. (2000), "Causal Parameters, Structural Equations, Treatment Effects and Randomized Evaluations of Social Programs," Mimeo. UC and Stanford. 
Heckman, J. and Vytlacil, E. (2001), "Policy-Relevant Treatment Effects," American Economic Review, 91 (May), 107-111.

Heckman J. J., Walker, J. (1990), "The relationship between wages and income and the timing and spacing of births: evidence from Swedish longitudinal data," Econometrica 52,1411-1441.

Heckman, J. J., and Willis, R. J. (1977), "A Beta-logistic Model for the Analysis of Sequential Labor Force Participation by Married Women," The Journal of Political Economy, 85, 27-58.

Hotz, V. J., Klerman, J. A., and Willis R. J. (1997) "The Economics of Fertility in Developed Countries," in Rosenzweig, M. and Stark, O. eds., Handbook of Population and Family Economics, Elsevier, Amsterdam, 275-347.

Hotz, V.J. and Miller, R. (1988), "An Empirical Analysis of Life Cycle Fertility and Female Labor Supply," Econometrica 56, 91-118.

Hyslop, D., (1999), "State Dependence, Serial Correlation and Heterogeneity in Intertemporal Labor Force Participation of Married Women," Econometrica, 67, 1255-1294.

Imbens, G. and Angrist, J. (1994), "Identification and Estimation of Local Average Treatment Effects." Econometrica 62, 467-76.

Juhn, C. and Murphy, K. M. (1997) "Wage Inequality and Family Labor Supply," Journal of Labor Economics, $72-97$.

Keane, M. (1992), "A Note on Identification in the Multinomial Probit Model," Journal of Business and Economics Statistics, 10, 193-200.

Lehrer, E. L. (1992), "The Impact of Children on Married Women's Labor Supply: Black-White Differentials Revisited, "Journal of Human Resources, 27, 422-444.

Leibowitz, A. (1974), "Education and the Allocation of Women's Time." in Education, Income, and Human Behavior, ed. F. Thomas Juster McGraw Hill, New York, 171-197.

Leibowitz, A., Klerman, J. A., and Waite, L. (1992), "Employment of New Mothers and Child Care Choice: Differences by Children's Age," Journal of Human Resources, 27, 112-123.

McCulloch, R., and Rossi, P. (1994), "An Exact Analysis of the Multinomial Probit Model," Jornal of Econometrics, 64, 207-240.

Michael, R. (1973), "Education and the Derived Demand for Children," Journal of Political Economy, 81, No. 2, Part 2: New Economic Approaches to Fertility, S128-S164.

Mincer, J. (1962), "Labor Force Participation of Married Women," in Aspects of Labor Economics, ed. H.G. Lewis, Princeton University Press, Princeton, NJ, 63-105.

Moffitt, R. (1984), "Optimal Life-Cycle Profiles of Fertility and Labor Supply", Research in Population Economics 5, 29-50.

Moffitt, R. (2005), "The Effect of Transfer Programs on Labor Supply in the Presence of Preference Heterogeneity and Variable Takeup," Mimeo, Johns Hopkins University 
Montgomery, M. R. and Casterline, J. B. (1996), "Social Learning, Social Influence, and New Models of Fertility," Population and Development Review, 22, Supplement: Fertility in the United States: New Patterns, New Theories, 151-175.

Newman, J. (1988), "A Stochastic Dynamic Model of Fertility", Research in Population Economics, 6, 41-68.

Newman J.L., McCulloch, D. (1984), "A hazard rate approach to the timing of births, " Econometrica 52, 939-961.

Rodgers, J. L. and Rowe, D. C. (1988), "Influence of Siblings on Adolescent Sexual Behavior," Developmental Psychology, 24, 722-728.

Rosenzweig, M. R., and Wolpin, K. I. (1980), "Life-Cycle Labor Supply and Fertility: Causal Inference from Household Models," The Journal of Political Economy, 88, 328-348.

Rowe, D. C., Rodgers, J. L., Meseck-Bushey, S., and St. John, C., (1989), "Sexual Behavior and Nonsexual Deviance: A Sibling Study of Their Relationship," Developmental Psychology, 25: 61-69.

Shapiro, D. and Mott, F. L. (1994), "Long-Term Employment and Earnings of Women in Relation to Employment Behavior Surrounding the First Birth," Journal of Human Resources 29, 248-275.

Troske, K.R., Voicu, A., (2010) "Joint estimation of sequential labor force participation and fertility decisions using Markov chain Monte Carlo techniques," Labour Economics, 17, 150-169.

Walker, J. (1995), "The Effect of Public Policies on Recent Swedish Fertility Behavior", Journal of Population Economics, 8, 223-251.

Willis, R. (1973), "A New Approach to the Economic Theory of Fertility Behavior." Journal of Political Economy, 81, No. 2, Part 2: New Economic Approaches to Fertility, S14-S64.

Wolpin, K. (1984), "An Estimable Dynamic Stochastic Model of Fertility and Child Mortality", Journal of Political Economy, 92, 852-874.

Yoon, Young-Hee and Waite, Linda J. (1994) "Converging Employment Patterns of Black, White, and Hispanic Women: Return to Work after First Birth," Jurnal of Marriage and the Family, Vol. 56, 209-217. 


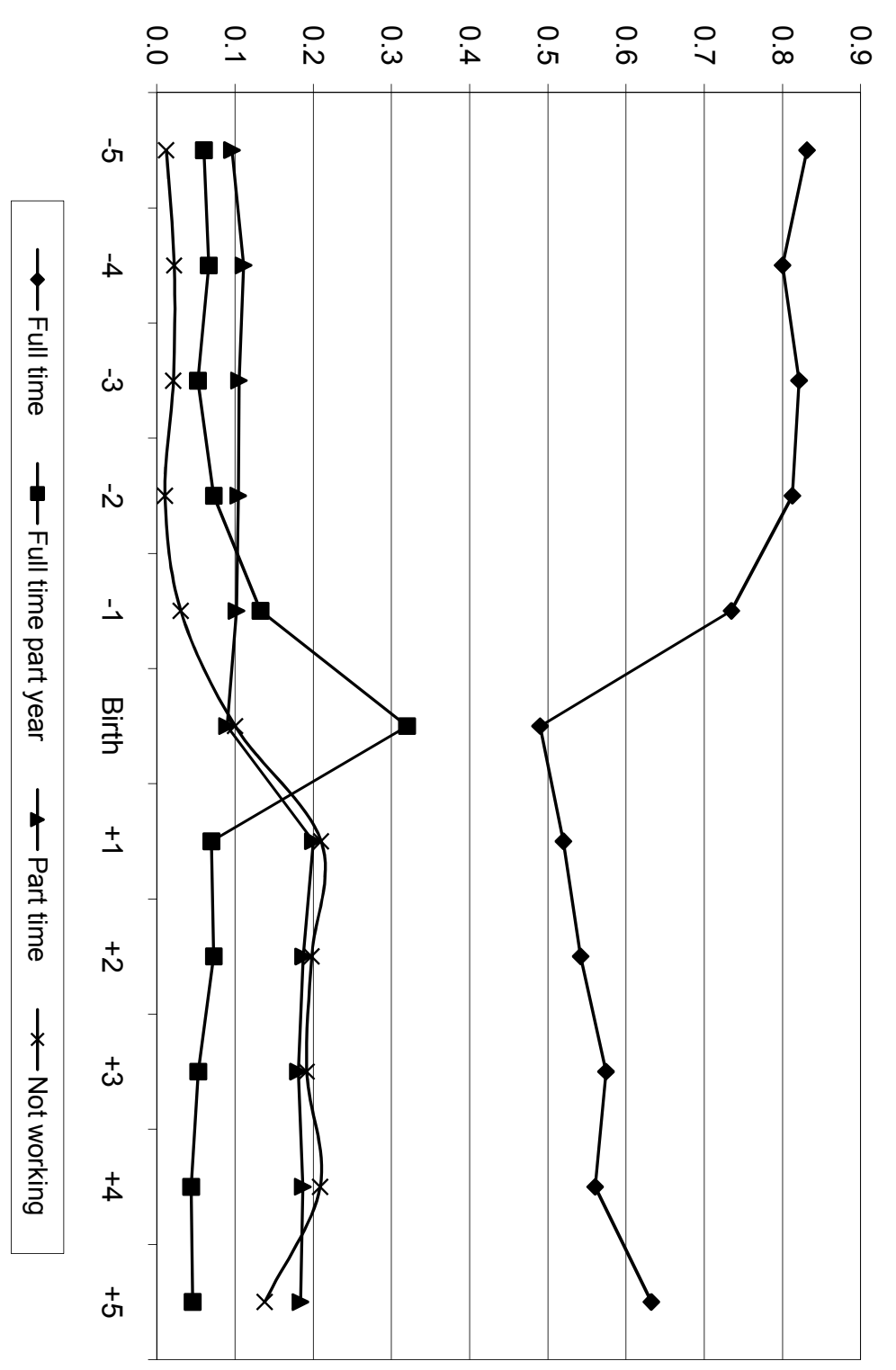

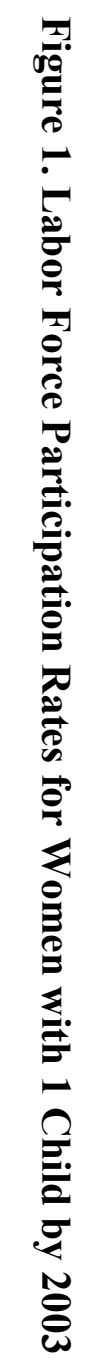


Figure 2. Number of children, timing of the first birth, and spacing of two births, by education and race

Women with 12 years of education

A. Number of children

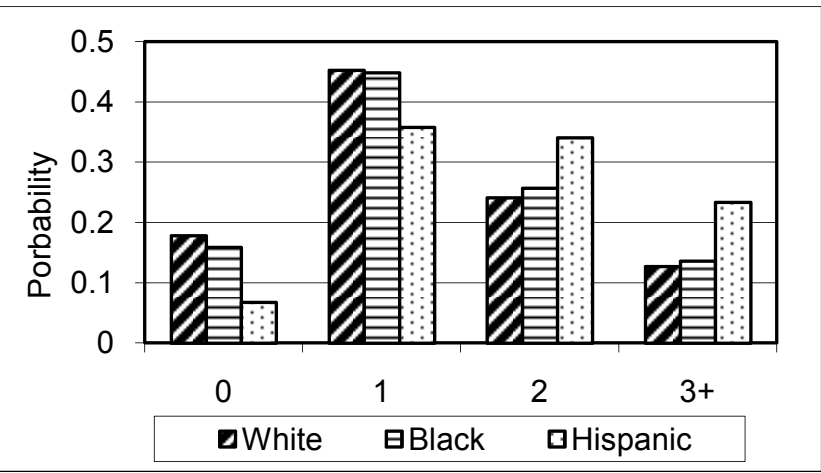

Women with 14 years of education

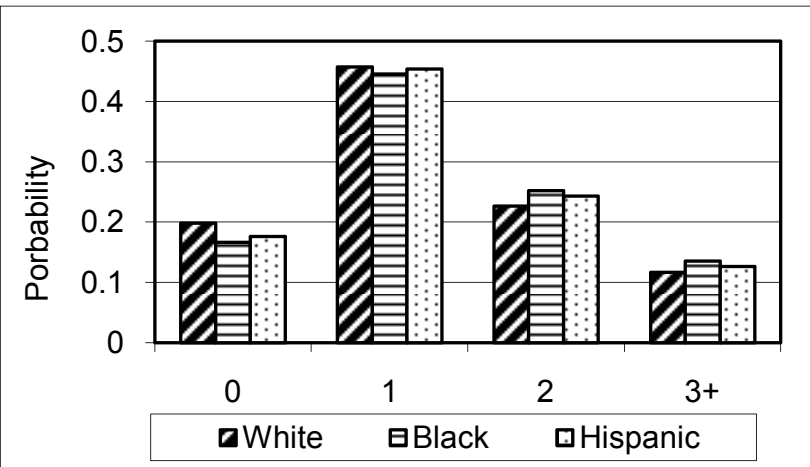

White women with 16 years of education

B. Timing of the first birth (years from marriage)
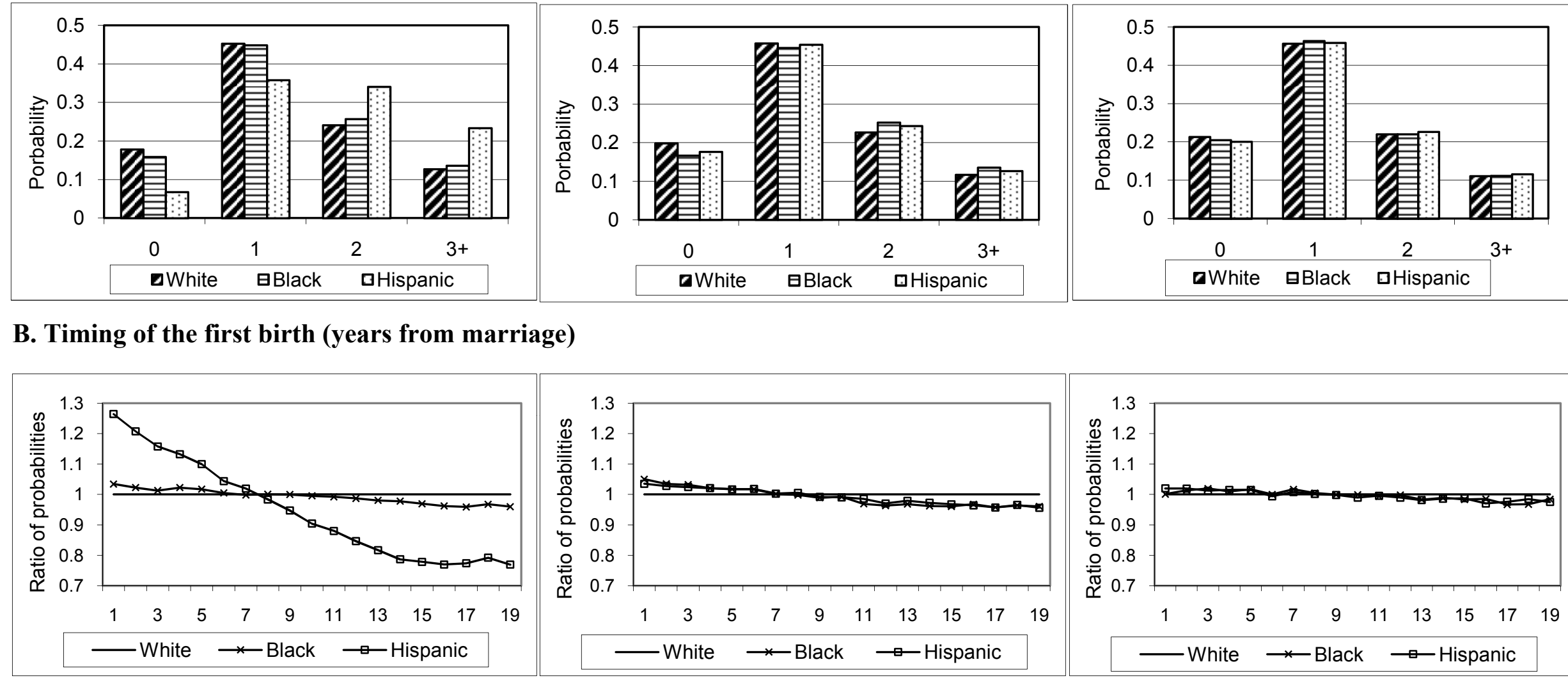

\section{Spacing of two births (years between births)}
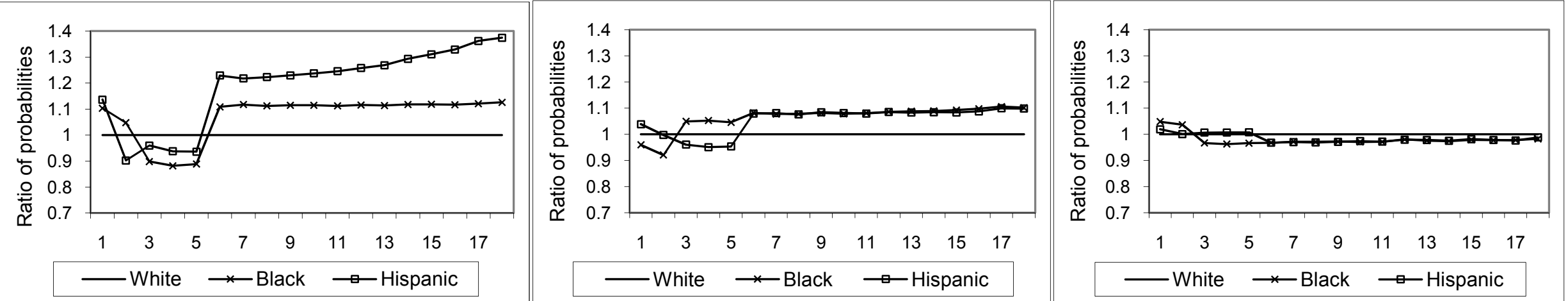
Figure 3. The effect of two children on the level of labor market involvement, white women with 12 years of education

Participation

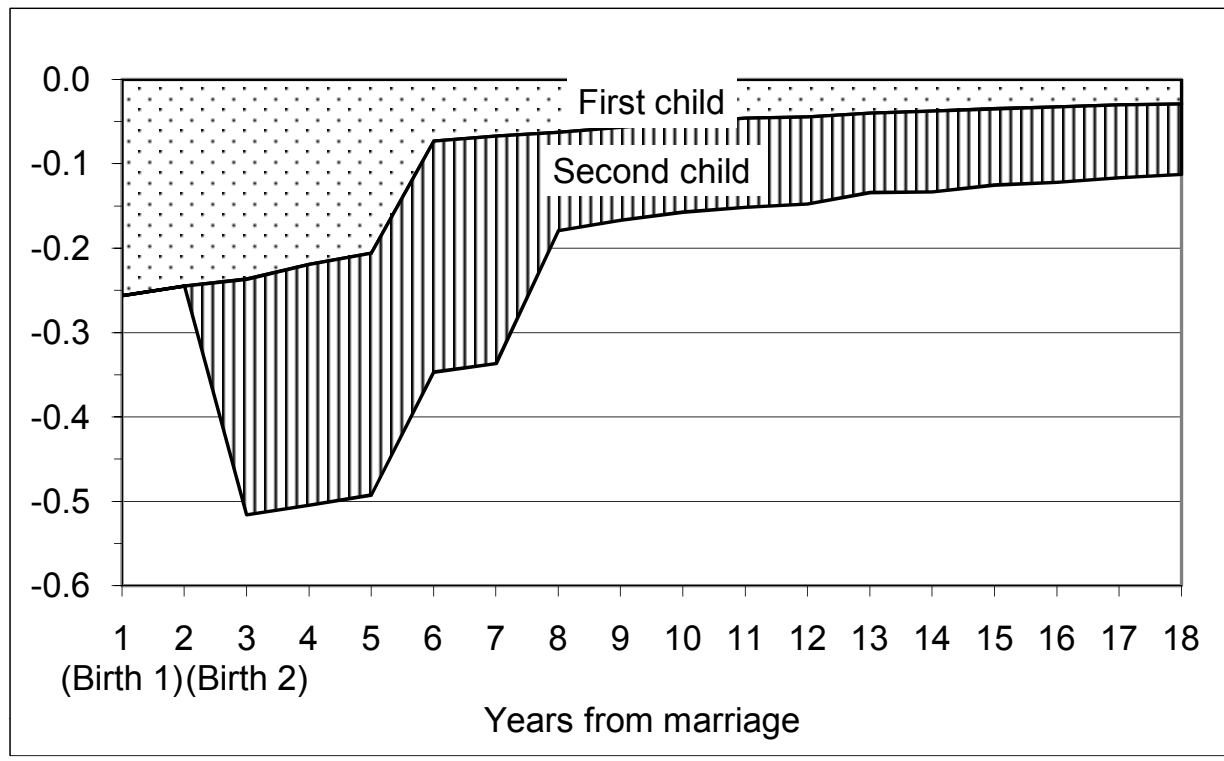

Full Time Part Year

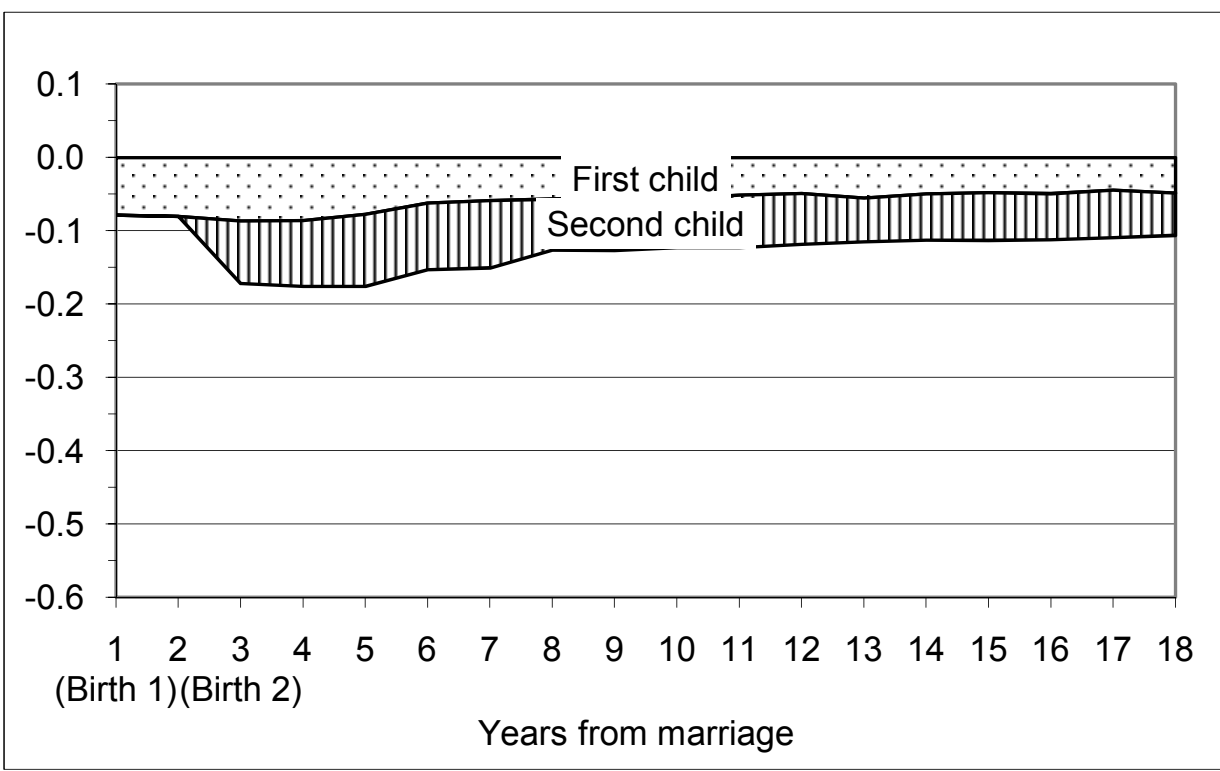

Full Time Part Year

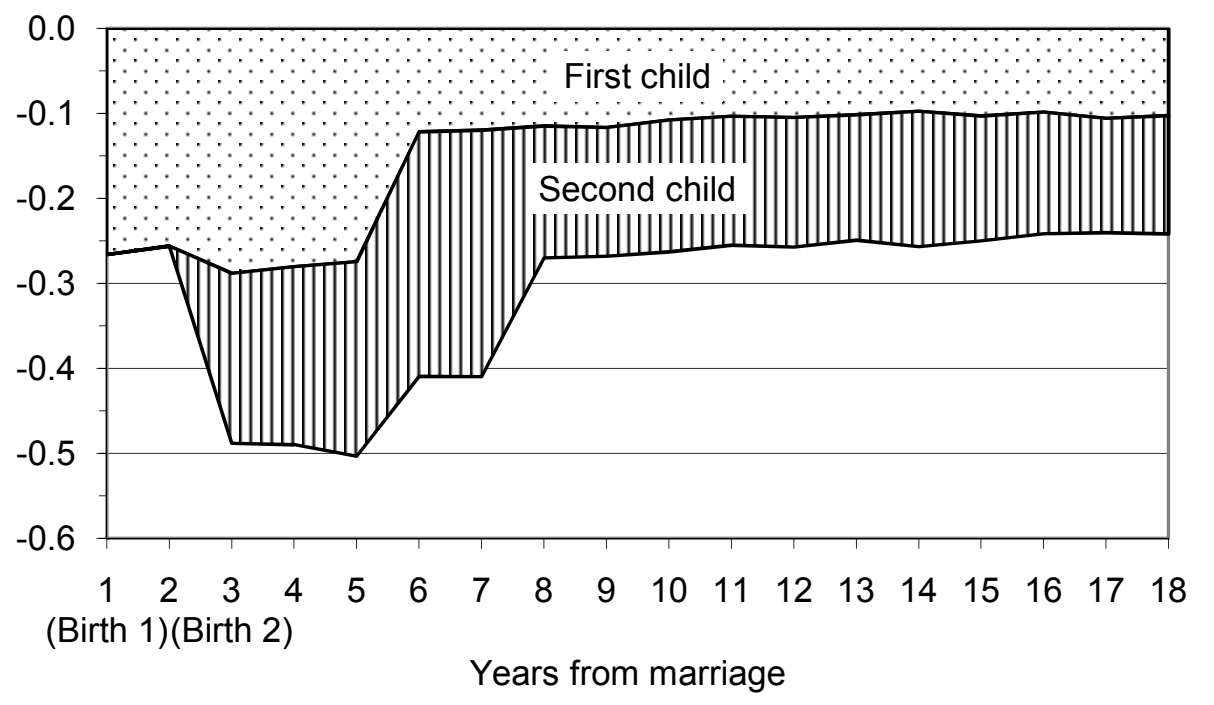

\section{Part Time}

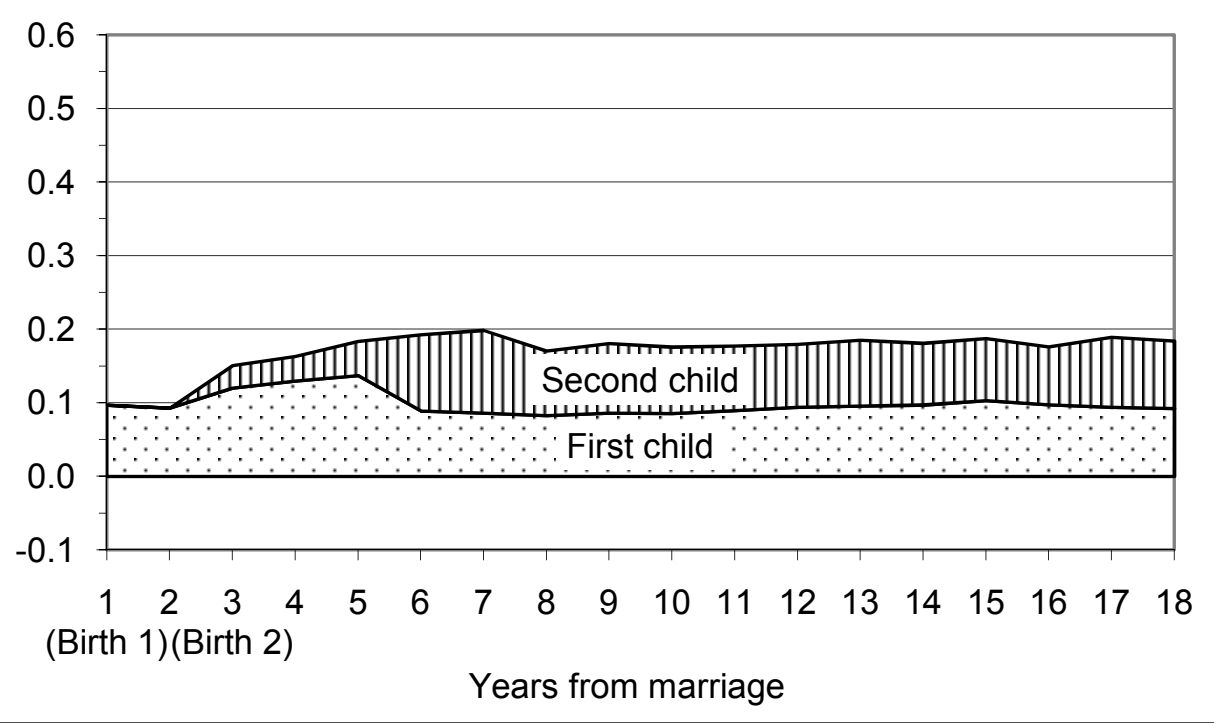


Table 1. Summary Statistics of the Variables in the Data Set

\section{A. Time-Varying Characteristics}

\begin{tabular}{|c|c|c|c|c|c|c|c|c|c|c|c|c|}
\hline \multirow[b]{2}{*}{$\begin{array}{c}\text { Year } \\
(1)\end{array}$} & \multirow[b]{2}{*}{$\begin{array}{c}\text { Number } \\
\text { at Risk } \\
\text { (2) }\end{array}$} & \multirow[b]{2}{*}{$\begin{array}{c}\text { Married } \\
(3) \\
\end{array}$} & \multirow[b]{2}{*}{$\begin{array}{l}\text { Avg. } \\
\text { Husband's } \\
\text { Income } \\
\text { (4) }\end{array}$} & \multirow[b]{2}{*}{$\begin{array}{c}\text { Avg. } \\
\text { Other } \\
\text { Income } \\
(5)\end{array}$} & \multirow[b]{2}{*}{$\begin{array}{c}\text { Birth Rate } \\
(6)\end{array}$} & \multicolumn{3}{|c|}{$\begin{array}{c}\text { Number of Children per Woman } \\
\text { at Risk, by Age }\end{array}$} & \multicolumn{4}{|c|}{ Labor Market Status } \\
\hline & & & & & & $\begin{array}{c}\text { Age } \\
0 \text { to } 1 \\
(7) \\
\end{array}$ & $\begin{array}{c}\text { Age } \\
2 \text { to } 4 \\
(8) \\
\end{array}$ & $\begin{array}{c}\text { Age } \\
5+ \\
(9) \\
\end{array}$ & $\begin{array}{l}\text { Full } \\
\text { Time } \\
(10) \\
\end{array}$ & $\begin{array}{c}\text { Full Time } \\
\text { Part Year } \\
\quad(11)\end{array}$ & $\begin{array}{l}\text { Part Time } \\
\quad(12) \\
\end{array}$ & $\begin{array}{c}\text { Not } \\
\text { Working } \\
(13)\end{array}$ \\
\hline 1979 & 116 & 0.00 & 0.0 & 72.4 & 0.00 & 0.00 & 0.00 & 0.00 & 0.67 & 0.18 & 0.11 & 0.03 \\
\hline 1980 & 185 & 0.22 & 1507.9 & 123.7 & 0.00 & 0.00 & 0.00 & 0.00 & 0.62 & 0.18 & 0.14 & 0.06 \\
\hline 1981 & 263 & 0.28 & 2488.6 & 119.8 & 0.02 & 0.02 & 0.00 & 0.00 & 0.57 & 0.15 & 0.19 & 0.08 \\
\hline 1982 & 340 & 0.34 & 2725.6 & 94.5 & 0.04 & 0.06 & 0.00 & 0.00 & 0.58 & 0.15 & 0.18 & 0.09 \\
\hline 1983 & 402 & 0.42 & 3924.8 & 221.7 & 0.05 & 0.08 & 0.01 & 0.00 & 0.58 & 0.16 & 0.15 & 0.10 \\
\hline 1984 & 455 & 0.49 & 5266.3 & 313.1 & 0.07 & 0.11 & 0.05 & 0.00 & 0.58 & 0.18 & 0.15 & 0.09 \\
\hline 1985 & 511 & 0.55 & 6157.3 & 526.6 & 0.09 & 0.15 & 0.08 & 0.00 & 0.59 & 0.15 & 0.18 & 0.08 \\
\hline 1986 & 561 & 0.57 & 8106.4 & 646.7 & 0.09 & 0.17 & 0.12 & 0.01 & 0.62 & 0.12 & 0.17 & 0.10 \\
\hline 1987 & 606 & 0.62 & 8749.0 & 704.5 & 0.09 & 0.17 & 0.16 & 0.03 & 0.61 & 0.14 & 0.17 & 0.08 \\
\hline 1988 & 624 & 0.67 & 10373.9 & 907.7 & 0.11 & 0.20 & 0.21 & 0.06 & 0.60 & 0.11 & 0.19 & 0.09 \\
\hline 1989 & 631 & 0.73 & 11684.7 & 963.5 & 0.12 & 0.23 & 0.24 & 0.12 & 0.59 & 0.12 & 0.17 & 0.12 \\
\hline 1990 & 636 & 0.77 & 13015.5 & 711.6 & 0.13 & 0.25 & 0.27 & 0.19 & 0.59 & 0.10 & 0.18 & 0.12 \\
\hline 1991 & 638 & 0.80 & 14435.0 & 668.0 & 0.13 & 0.26 & 0.32 & 0.26 & 0.55 & 0.11 & 0.20 & 0.14 \\
\hline 1992 & 639 & 0.84 & 15547.3 & 698.6 & 0.13 & 0.27 & 0.35 & 0.35 & 0.55 & 0.09 & 0.23 & 0.14 \\
\hline 1993 & 642 & 0.86 & 15981.3 & 1123.9 & 0.13 & 0.27 & 0.38 & 0.45 & 0.52 & 0.09 & 0.22 & 0.16 \\
\hline 1994 & 643 & 0.89 & 18432.9 & 2213.6 & 0.13 & 0.26 & 0.39 & 0.57 & 0.52 & 0.08 & 0.22 & 0.19 \\
\hline 1995 & 644 & 0.91 & 18083.1 & 2066.9 & 0.12 & 0.25 & 0.40 & 0.70 & 0.53 & 0.07 & 0.21 & 0.19 \\
\hline 1996 & 644 & 0.93 & 20263.3 & 2104.9 & 0.10 & 0.22 & 0.39 & 0.83 & 0.49 & 0.09 & 0.23 & 0.19 \\
\hline 1997 & 645 & 0.94 & 19878.5 & 1481.3 & 0.09 & 0.19 & 0.38 & 0.96 & 0.50 & 0.07 & 0.23 & 0.20 \\
\hline 1998 & 645 & 0.95 & 21807.5 & 2149.2 & 0.09 & 0.18 & 0.34 & 1.09 & 0.52 & 0.05 & 0.23 & 0.20 \\
\hline 1999 & 645 & 0.96 & 19960.9 & 2291.8 & 0.06 & 0.15 & 0.31 & 1.22 & 0.52 & 0.05 & 0.23 & 0.21 \\
\hline 2000 & 645 & 0.97 & 23862.0 & 2768.1 & 0.06 & 0.12 & 0.27 & 1.34 & 0.51 & 0.04 & 0.24 & 0.20 \\
\hline 2001 & 645 & 0.98 & 22397.7 & 1829.4 & 0.03 & 0.08 & 0.24 & 1.44 & 0.53 & 0.04 & 0.24 & 0.19 \\
\hline 2002 & 645 & 0.99 & 24945.3 & 2838.3 & 0.03 & 0.06 & 0.20 & 1.53 & 0.52 & 0.06 & 0.24 & 0.18 \\
\hline 2003 & 645 & 1.00 & 23925.9 & 2315.4 & 0.02 & 0.05 & 0.14 & 1.61 & 0.51 & 0.06 & 0.22 & 0.21 \\
\hline
\end{tabular}

B. Time-Invariant Personal Characteristics and Family Backgound Variables

\begin{tabular}{|c|c|c|c|c|c|c|c|}
\hline Education & $\%$ & Race & $\%$ & Mother's LM status & $\%$ & Parents' education & $\%$ \\
\hline$<=12$ yrs & 36.4 & White & 69.9 & Full-time & 31.2 & None college & 74.6 \\
\hline 13-15yrs & 26.7 & Black & 13.8 & Other & 68.8 & One college & 16.0 \\
\hline$>=16$ yrs & 36.9 & Hispanic & 16.3 & & & Both college & 9.5 \\
\hline
\end{tabular}




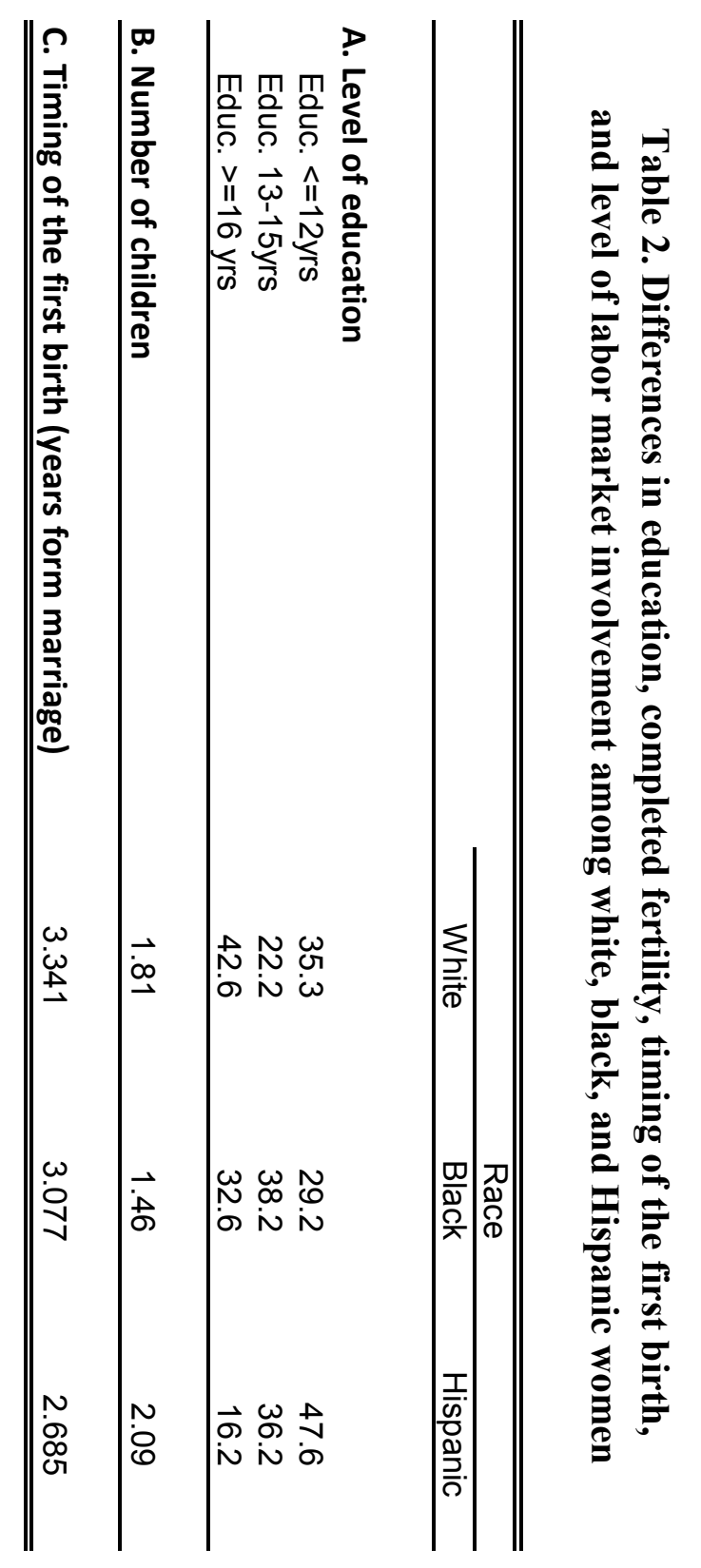


Table 3. The level of labor market involvement before the birth of the first child by race and education

\begin{tabular}{|c|c|c|c|c|c|c|c|c|c|}
\hline \multicolumn{10}{|c|}{ A. Women with 12 years of education } \\
\hline & \multicolumn{3}{|c|}{$\begin{array}{l}\text { First birth in year } 3 \\
\text { (marriage year }+1)\end{array}$} & \multicolumn{3}{|c|}{$\begin{array}{l}\text { First birth in year } 9 \\
(\text { marriage year }+7)\end{array}$} & \multicolumn{3}{|c|}{$\begin{array}{c}\text { Change } \\
\text { from year } 3 \text { to year } 9 \\
\end{array}$} \\
\hline & $\begin{array}{l}\text { White } \\
(1)\end{array}$ & $\begin{array}{c}\text { Black } \\
(2)\end{array}$ & $\begin{array}{c}\text { Hispanic } \\
\text { (3) }\end{array}$ & $\begin{array}{l}\text { White } \\
(4)\end{array}$ & $\begin{array}{c}\text { Black } \\
(5)\end{array}$ & $\begin{array}{c}\text { Hispanic } \\
(6)\end{array}$ & $\begin{array}{l}\text { White } \\
(7)\end{array}$ & $\begin{array}{c}\text { Black } \\
(8)\end{array}$ & $\begin{array}{c}\text { Hispanic } \\
(9)\end{array}$ \\
\hline Participation & 0.921 & 0.874 & 0.879 & 0.974 & 0.952 & 0.955 & 0.053 & 0.078 & 0.076 \\
\hline Full time & 0.586 & 0.474 & 0.386 & 0.606 & 0.509 & 0.415 & 0.019 & 0.035 & 0.028 \\
\hline Full time part year & 0.196 & 0.234 & 0.306 & 0.206 & 0.247 & 0.326 & 0.010 & 0.013 & 0.020 \\
\hline Part time & 0.139 & 0.167 & 0.187 & 0.163 & 0.197 & 0.214 & 0.024 & 0.030 & 0.027 \\
\hline
\end{tabular}

\begin{tabular}{|c|c|c|c|c|c|c|c|c|c|}
\hline \multicolumn{10}{|c|}{ B. Women with 14 years of education } \\
\hline & \multicolumn{3}{|c|}{$\begin{array}{l}\text { First birth in year } 3 \\
(\text { marriage year }+1)\end{array}$} & \multicolumn{3}{|c|}{$\begin{array}{l}\text { First birth in year } 9 \\
(\text { marriage year }+7)\end{array}$} & \multicolumn{3}{|c|}{$\begin{array}{c}\text { Change } \\
\text { from year } 3 \text { to year } 9\end{array}$} \\
\hline & $\begin{array}{l}\text { White } \\
(1)\end{array}$ & $\begin{array}{c}\text { Black } \\
(2)\end{array}$ & $\begin{array}{c}\text { Hispanic } \\
(3)\end{array}$ & $\begin{array}{c}\text { White } \\
(4)\end{array}$ & $\begin{array}{c}\text { Black } \\
(5)\end{array}$ & $\begin{array}{c}\text { Hispanic } \\
(6)\end{array}$ & $\begin{array}{l}\text { White } \\
(7)\end{array}$ & $\begin{array}{c}\text { Black } \\
(8)\end{array}$ & $\begin{array}{c}\text { Hispanic } \\
\text { (9) }\end{array}$ \\
\hline Participation & 0.960 & 0.955 & 0.948 & 0.988 & 0.987 & 0.984 & 0.028 & 0.032 & 0.036 \\
\hline Full time & 0.693 & 0.619 & 0.636 & 0.687 & 0.623 & 0.638 & -0.006 & 0.004 & 0.002 \\
\hline Full time part year & 0.167 & 0.218 & 0.193 & 0.175 & 0.222 & 0.204 & 0.008 & 0.004 & 0.010 \\
\hline Part time & 0.100 & 0.119 & 0.118 & 0.126 & 0.142 & 0.142 & 0.027 & 0.024 & 0.024 \\
\hline
\end{tabular}

\begin{tabular}{|c|c|c|c|c|c|c|c|c|c|}
\hline \multicolumn{10}{|c|}{ C. Women with 16 years of education } \\
\hline & \multicolumn{3}{|c|}{$\begin{array}{l}\text { First birth in year } 3 \\
(\text { marriage year }+1) \\
\end{array}$} & \multicolumn{3}{|c|}{$\begin{array}{l}\text { First birth in year } 9 \\
(\text { marriage year }+7)\end{array}$} & \multicolumn{3}{|c|}{$\begin{array}{c}\text { Change } \\
\text { from year } 3 \text { to year } 9\end{array}$} \\
\hline & $\begin{array}{l}\text { White } \\
(1)\end{array}$ & $\begin{array}{c}\text { Black } \\
(2)\end{array}$ & $\begin{array}{c}\text { Hispanic } \\
\text { (3) }\end{array}$ & $\begin{array}{c}\text { White } \\
(4)\end{array}$ & $\begin{array}{c}\text { Black } \\
(5)\end{array}$ & $\begin{array}{c}\text { Hispanic } \\
(6)\end{array}$ & $\begin{array}{c}\text { White } \\
(7)\end{array}$ & $\begin{array}{c}\text { Black } \\
(8)\end{array}$ & $\begin{array}{c}\text { Hispanic } \\
(9)\end{array}$ \\
\hline Participation & 0.975 & 0.965 & 0.967 & 0.993 & 0.990 & 0.990 & 0.018 & 0.025 & 0.024 \\
\hline Full time & 0.745 & 0.643 & 0.659 & 0.731 & 0.641 & 0.649 & -0.014 & -0.001 & -0.010 \\
\hline Full time part year & 0.150 & 0.212 & 0.199 & 0.159 & 0.214 & 0.206 & 0.009 & 0.002 & 0.008 \\
\hline Part time & 0.080 & 0.110 & 0.109 & 0.103 & 0.135 & 0.135 & 0.023 & 0.025 & 0.026 \\
\hline
\end{tabular}



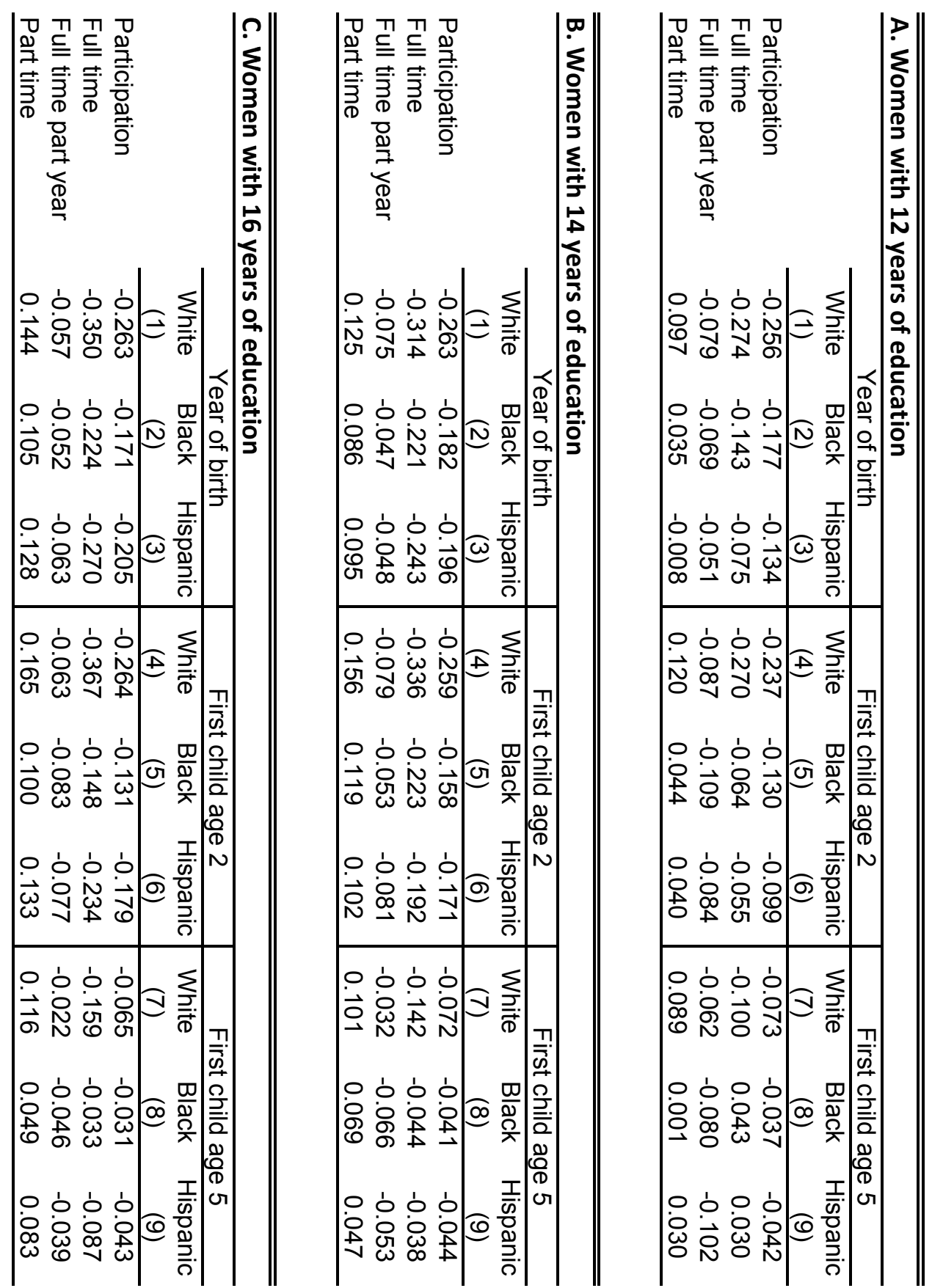

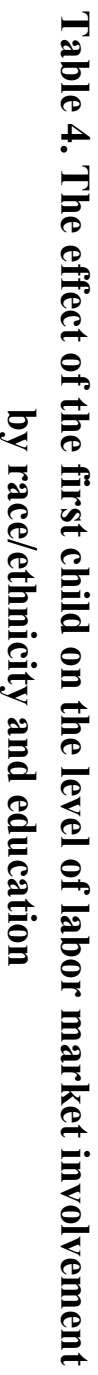



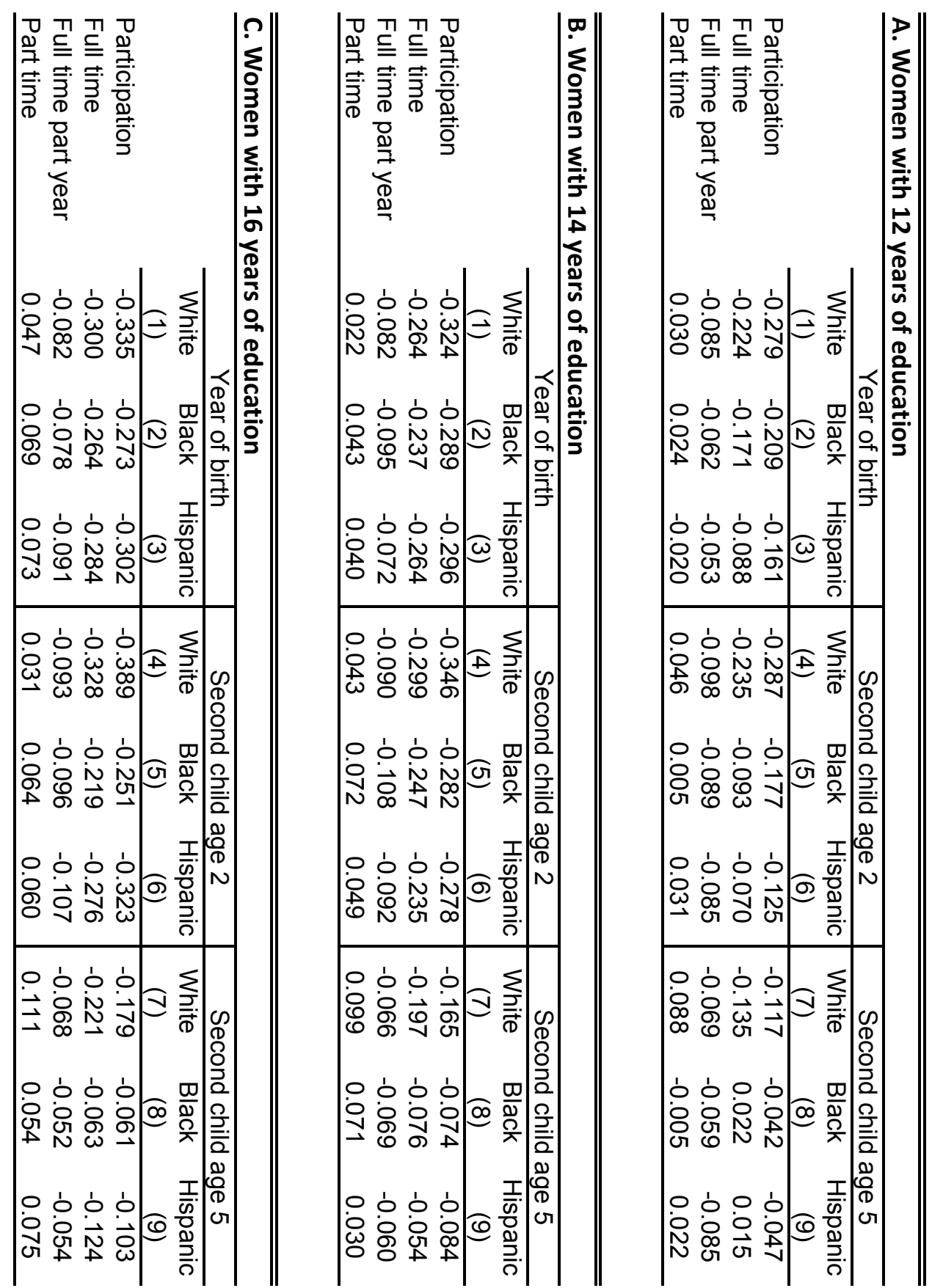

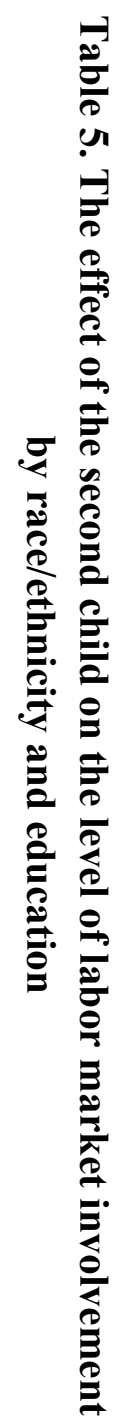


Table 6. The effects of the timing and spacing of births on the dynamics of the level of labor market involvement around the first and the second births, by race/ethnicity and education

\begin{tabular}{|c|c|c|c|c|c|c|}
\hline \multicolumn{7}{|c|}{ A. Women with 12 years of education } \\
\hline & \multicolumn{3}{|c|}{$\begin{array}{l}\text { The effect of the first child in the year of birth } \\
\text { First birth in year } 9 \text { compared to first birth in year } 3\end{array}$} & \multicolumn{3}{|c|}{$\begin{array}{l}\text { The effect of the second child in the year of birth } \\
\text { Second birth in year } 9 \text { compared to second birth in year } 5\end{array}$} \\
\hline & $\begin{array}{c}\text { White } \\
\text { (1) }\end{array}$ & $\begin{array}{c}\text { Black } \\
(2)\end{array}$ & $\begin{array}{l}\text { Hispanic } \\
\text { (3) }\end{array}$ & $\begin{array}{c}\text { White } \\
(4)\end{array}$ & $\begin{array}{c}\text { Black } \\
(5)\end{array}$ & $\begin{array}{l}\text { Hispanic } \\
\text { (6) }\end{array}$ \\
\hline Participation & 0.113 & 0.074 & 0.060 & 0.036 & 0.075 & 0.053 \\
\hline Full time & 0.052 & 0.019 & 0.013 & -0.027 & 0.028 & 0.018 \\
\hline Full time part year & 0.031 & 0.029 & 0.024 & 0.001 & 0.015 & 0.006 \\
\hline Part time & 0.030 & 0.026 & 0.023 & 0.062 & 0.031 & 0.028 \\
\hline
\end{tabular}

\begin{tabular}{|c|c|c|c|c|c|c|}
\hline \multicolumn{7}{|c|}{ B. Women with 14 years of education } \\
\hline & \multicolumn{3}{|c|}{$\begin{array}{l}\text { The effect of the first child in the year of birth } \\
\text { First birth in year } 9 \text { compared to first birth in year } 3\end{array}$} & \multicolumn{3}{|c|}{$\begin{array}{l}\text { The effect of the second child in the year of birth } \\
\text { Second birth in year } 9 \text { compared to second birth in year } 5\end{array}$} \\
\hline & $\begin{array}{l}\text { White } \\
(1)\end{array}$ & $\begin{array}{c}\text { Black } \\
(2)\end{array}$ & $\begin{array}{l}\text { Hispanic } \\
\text { (3) }\end{array}$ & $\begin{array}{c}\text { White } \\
(4)\end{array}$ & $\begin{array}{c}\text { Black } \\
(5)\end{array}$ & $\begin{array}{l}\text { Hispanic } \\
(6)\end{array}$ \\
\hline Participation & 0.125 & 0.095 & 0.099 & 0.042 & 0.118 & 0.108 \\
\hline Full time & 0.067 & 0.039 & 0.041 & -0.057 & 0.004 & 0.017 \\
\hline Full time part year & 0.026 & 0.030 & 0.032 & -0.008 & 0.042 & 0.023 \\
\hline Part time & 0.033 & 0.026 & 0.026 & 0.108 & 0.072 & 0.068 \\
\hline
\end{tabular}

\begin{tabular}{|c|c|c|c|c|c|c|}
\hline \multicolumn{7}{|c|}{ C. Women with 16 years of education } \\
\hline & \multicolumn{3}{|c|}{$\begin{array}{l}\text { The effect of the first child in the year of birth } \\
\text { First birth in year } 9 \text { compared to first birth in year } 3\end{array}$} & \multicolumn{3}{|c|}{$\begin{array}{l}\text { The effect of the second child in the year of birth } \\
\text { Second birth in year } 9 \text { compared to second birth in year } 5\end{array}$} \\
\hline & $\begin{array}{c}\text { White } \\
\text { (1) }\end{array}$ & $\begin{array}{c}\text { Black } \\
(2)\end{array}$ & $\begin{array}{l}\text { Hispanic } \\
\text { (3) }\end{array}$ & $\begin{array}{c}\text { White } \\
(4)\end{array}$ & $\begin{array}{c}\text { Black } \\
(5)\end{array}$ & $\begin{array}{l}\text { Hispanic } \\
(6)\end{array}$ \\
\hline Participation & 0.137 & 0.091 & 0.109 & 0.034 & 0.116 & 0.085 \\
\hline Full time & 0.067 & 0.039 & 0.049 & -0.068 & 0.047 & 0.003 \\
\hline Full time part year & 0.034 & 0.024 & 0.039 & -0.009 & 0.018 & 0.017 \\
\hline Part time & 0.036 & 0.028 & 0.021 & 0.112 & 0.050 & 0.064 \\
\hline
\end{tabular}


Table 7. The dynamics of the level of labor market involvement after the first birth by race/ethnicity and education

\begin{tabular}{|c|c|c|c|c|c|c|c|c|c|c|c|c|}
\hline \multicolumn{13}{|c|}{ A. Women with 12 years of education } \\
\hline & \multicolumn{3}{|c|}{ Before first birth } & \multicolumn{3}{|c|}{ Year of birth } & \multicolumn{3}{|c|}{ First child age 2} & \multicolumn{3}{|c|}{ First child age 5} \\
\hline & $\begin{array}{c}\text { White } \\
(1)\end{array}$ & $\begin{array}{c}\text { Black } \\
(2) \\
\end{array}$ & $\begin{array}{c}\text { Hispanic } \\
(3)\end{array}$ & $\begin{array}{c}\text { White } \\
(4)\end{array}$ & $\begin{array}{c}\text { Black } \\
(5)\end{array}$ & $\begin{array}{c}\text { Hispanic } \\
(6)\end{array}$ & $\begin{array}{c}\text { White } \\
(7)\end{array}$ & $\begin{array}{c}\text { Black } \\
(8)\end{array}$ & $\begin{array}{c}\text { Hispanic } \\
(9)\end{array}$ & $\begin{array}{l}\text { White } \\
(10)\end{array}$ & $\begin{array}{c}\text { Black } \\
(11)\end{array}$ & $\begin{array}{c}\text { Hispanic } \\
(12)\end{array}$ \\
\hline Participation & 0.921 & 0.874 & 0.879 & 0.677 & 0.716 & 0.765 & 0.718 & 0.793 & 0.828 & 0.901 & 0.916 & 0.913 \\
\hline Full time & 0.586 & 0.474 & 0.386 & 0.310 & 0.333 & 0.314 & 0.321 & 0.426 & 0.349 & 0.502 & 0.546 & 0.447 \\
\hline Full time part year & 0.196 & 0.234 & 0.306 & 0.120 & 0.164 & 0.257 & 0.116 & 0.132 & 0.227 & 0.146 & 0.170 & 0.219 \\
\hline Part time & 0.139 & 0.167 & 0.187 & 0.248 & 0.219 & 0.194 & 0.281 & 0.236 & 0.253 & 0.253 & 0.200 & 0.247 \\
\hline
\end{tabular}

\begin{tabular}{|c|c|c|c|c|c|c|c|c|c|c|c|c|}
\hline \multicolumn{13}{|c|}{ B. Women with 14 years of education } \\
\hline & \multicolumn{3}{|c|}{ Before first birth } & \multicolumn{3}{|c|}{ Year of birth } & \multicolumn{3}{|c|}{ First child age 2} & \multicolumn{3}{|c|}{ First child age 5} \\
\hline & $\begin{array}{l}\text { White } \\
\text { (1) }\end{array}$ & $\begin{array}{c}\text { Black } \\
\text { (2) }\end{array}$ & $\begin{array}{c}\text { Hispanic } \\
\text { (3) }\end{array}$ & $\begin{array}{c}\text { White } \\
(4)\end{array}$ & $\begin{array}{c}\text { Black } \\
\text { (5) }\end{array}$ & $\begin{array}{c}\text { Hispanic } \\
\text { (6) }\end{array}$ & $\begin{array}{c}\text { White } \\
(7)\end{array}$ & $\begin{array}{c}\text { Black } \\
\text { (8) }\end{array}$ & $\begin{array}{c}\text { Hispanic } \\
\text { (9) }\end{array}$ & $\begin{array}{c}\text { White } \\
(10)\end{array}$ & $\begin{array}{c}\text { Black } \\
(11)\end{array}$ & $\begin{array}{c}\text { Hispanic } \\
\text { (12) }\end{array}$ \\
\hline Participation & 0.960 & 0.955 & 0.948 & 0.702 & 0.781 & 0.759 & 0.718 & 0.818 & 0.800 & 0.916 & 0.946 & 0.940 \\
\hline Full time & 0.693 & 0.619 & 0.636 & 0.369 & 0.392 & 0.381 & 0.343 & 0.398 & 0.434 & 0.544 & 0.580 & 0.595 \\
\hline Full time part year & 0.167 & 0.218 & 0.193 & 0.095 & 0.170 & 0.149 & 0.095 & 0.163 & 0.119 & 0.145 & 0.153 & 0.152 \\
\hline Part time & 0.100 & 0.119 & 0.118 & 0.239 & 0.219 & 0.229 & 0.280 & 0.257 & 0.247 & 0.227 & 0.212 & 0.194 \\
\hline
\end{tabular}

\begin{tabular}{|c|c|c|c|c|c|c|c|c|c|c|c|c|}
\hline \multicolumn{13}{|c|}{ C. Women with 16 years of education } \\
\hline & \multicolumn{3}{|c|}{ Before first birth } & \multicolumn{3}{|c|}{ Year of birth } & \multicolumn{3}{|c|}{ First child age 2} & \multicolumn{3}{|c|}{ First child age 5} \\
\hline & $\begin{array}{l}\text { White } \\
(1)\end{array}$ & $\begin{array}{c}\text { Black } \\
(2)\end{array}$ & $\begin{array}{c}\text { Hispanic } \\
(3)\end{array}$ & $\begin{array}{l}\text { White } \\
(4)\end{array}$ & $\begin{array}{c}\text { Black } \\
(5)\end{array}$ & $\begin{array}{c}\text { Hispanic } \\
(6)\end{array}$ & $\begin{array}{c}\text { White } \\
(7)\end{array}$ & $\begin{array}{c}\text { Black } \\
(8)\end{array}$ & $\begin{array}{c}\text { Hispanic } \\
(9)\end{array}$ & $\begin{array}{l}\text { White } \\
(10)\end{array}$ & $\begin{array}{c}\text { Black } \\
(11)\end{array}$ & $\begin{array}{c}\text { Hispanic } \\
(12)\end{array}$ \\
\hline Participation & 0.975 & 0.965 & 0.967 & 0.715 & 0.800 & 0.767 & 0.721 & 0.850 & 0.803 & 0.928 & 0.959 & 0.948 \\
\hline Full time & 0.745 & 0.643 & 0.659 & 0.379 & 0.413 & 0.377 & 0.360 & 0.484 & 0.415 & 0.573 & 0.605 & 0.570 \\
\hline Full time part year & 0.150 & 0.212 & 0.199 & 0.098 & 0.158 & 0.141 & 0.093 & 0.131 & 0.126 & 0.135 & 0.169 & 0.163 \\
\hline Part time & 0.080 & 0.110 & 0.109 & 0.238 & 0.229 & 0.248 & 0.268 & 0.235 & 0.262 & 0.220 & 0.185 & 0.214 \\
\hline
\end{tabular}


Table 8. The dynamics of the level of labor market involvement after the second birth by race/ethnicity and education

\begin{tabular}{lccc|ccc|ccc|ccc}
\hline \hline A. Women with 12 years of education \\
\hline
\end{tabular}

\begin{tabular}{|c|c|c|c|c|c|c|c|c|c|c|c|c|}
\hline \multicolumn{13}{|c|}{ B. Women with 14 years of education } \\
\hline & \multicolumn{3}{|c|}{ Before first birth } & \multicolumn{3}{|c|}{ Year of second birth } & \multicolumn{3}{|c|}{ Second child age 2} & \multicolumn{3}{|c|}{ Second child age 5} \\
\hline & $\begin{array}{l}\text { White } \\
\text { (1) }\end{array}$ & $\begin{array}{c}\text { Black } \\
(2)\end{array}$ & $\begin{array}{c}\text { Hispanic } \\
\text { (3) }\end{array}$ & $\begin{array}{l}\text { White } \\
(4)\end{array}$ & $\begin{array}{c}\text { Black } \\
(5)\end{array}$ & $\begin{array}{c}\text { Hispanic } \\
(6)\end{array}$ & $\begin{array}{l}\text { White } \\
(7)\end{array}$ & $\begin{array}{c}\text { Black } \\
(8)\end{array}$ & $\begin{array}{c}\text { Hispanic } \\
(9)\end{array}$ & $\begin{array}{l}\text { White } \\
(10)\end{array}$ & $\begin{array}{c}\text { Black } \\
(11)\end{array}$ & $\begin{array}{c}\text { Hispanic } \\
\text { (12) }\end{array}$ \\
\hline Partic & 0.960 & 0.955 & 0.948 & 0.394 & 0.530 & 0.504 & 0.409 & 0.570 & 0.558 & 0.769 & 0.884 & 0.870 \\
\hline Full tim & 0.693 & 0.619 & 0.636 & 0.080 & 0.161 & 0.170 & 0.066 & 0.168 & 0.219 & 0.367 & 0.509 & 0.541 \\
\hline Full time part year & 0.167 & 0.218 & 0.193 & 0.013 & 0.068 & 0.047 & 0.012 & 0.064 & 0.033 & 0.080 & 0.084 & 0.103 \\
\hline Part time & 0.100 & 0.119 & 0.118 & 0.302 & 0.300 & 0.287 & 0.331 & 0.339 & 0.306 & 0.322 & 0.290 & 0.226 \\
\hline
\end{tabular}

\begin{tabular}{|c|c|c|c|c|c|c|c|c|c|c|c|c|}
\hline \multicolumn{13}{|c|}{ C. Women with 16 years of education } \\
\hline & \multicolumn{3}{|c|}{ Before first birth } & \multicolumn{3}{|c|}{ Year of second birth } & \multicolumn{3}{|c|}{ Second child age 2} & \multicolumn{3}{|c|}{ Second child age 5} \\
\hline & $\begin{array}{l}\text { White } \\
\text { (1) }\end{array}$ & $\begin{array}{c}\text { Black } \\
(2)\end{array}$ & $\begin{array}{c}\text { Hispanic } \\
(3)\end{array}$ & $\begin{array}{c}\text { White } \\
(4)\end{array}$ & $\begin{array}{c}\text { Black } \\
(5)\end{array}$ & $\begin{array}{c}\text { Hispanic } \\
(6)\end{array}$ & $\begin{array}{c}\text { White } \\
(7)\end{array}$ & $\begin{array}{c}\text { Black } \\
(8)\end{array}$ & $\begin{array}{c}\text { Hispanic } \\
(9) \\
\end{array}$ & $\begin{array}{l}\text { White } \\
(10)\end{array}$ & $\begin{array}{c}\text { Black } \\
(11)\end{array}$ & $\begin{array}{c}\text { Hispanic } \\
(12)\end{array}$ \\
\hline Participation & 0.975 & 0.965 & 0.967 & 0.386 & 0.577 & 0.501 & 0.371 & 0.629 & 0.513 & 0.764 & 0.909 & 0.858 \\
\hline Full time & 0.745 & 0.643 & 0.659 & 0.060 & 0.221 & 0.131 & 0.052 & 0.283 & 0.149 & 0.358 & 0.561 & 0.463 \\
\hline Full time part year & 0.150 & 0.212 & 0.199 & 0.011 & 0.053 & 0.035 & 0.011 & 0.043 & 0.030 & 0.073 & 0.113 & 0.114 \\
\hline Part time & 0.080 & 0.110 & 0.109 & 0.316 & 0.304 & 0.336 & 0.308 & 0.303 & 0.334 & 0.333 & 0.235 & 0.281 \\
\hline
\end{tabular}




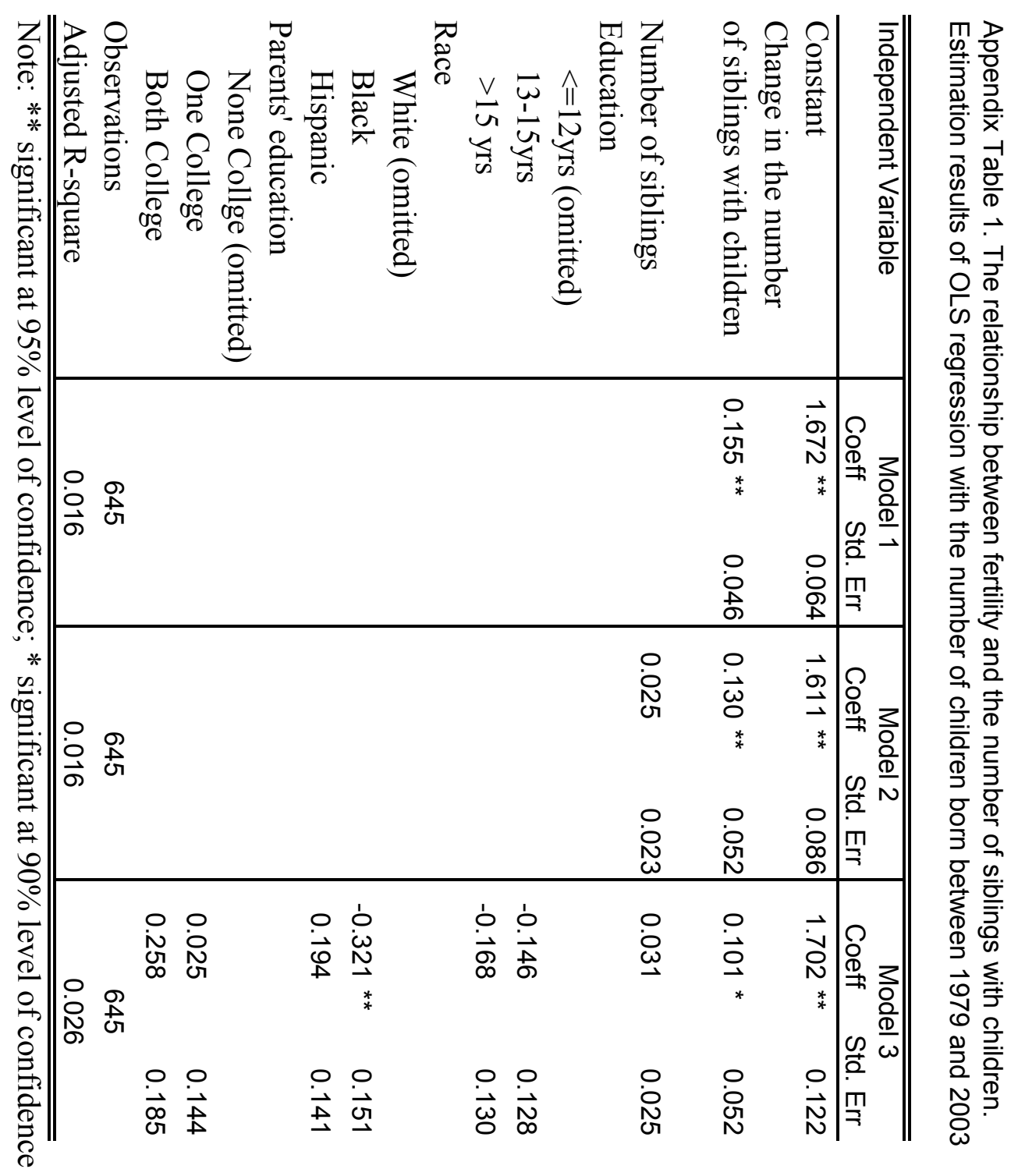




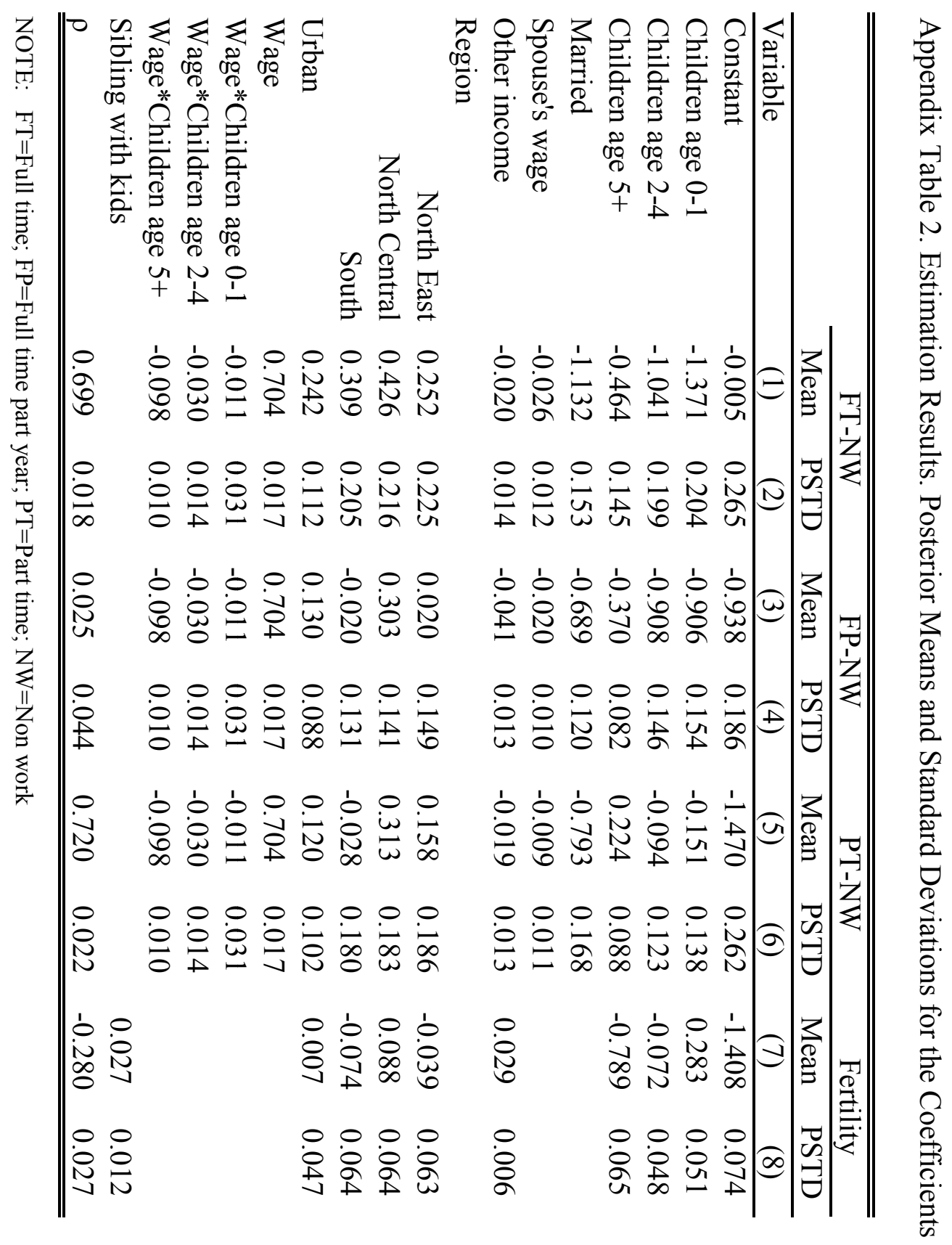


Appendix Table 3. Posterior Means of Random Coefficients. The effects of race/ethnicity and education

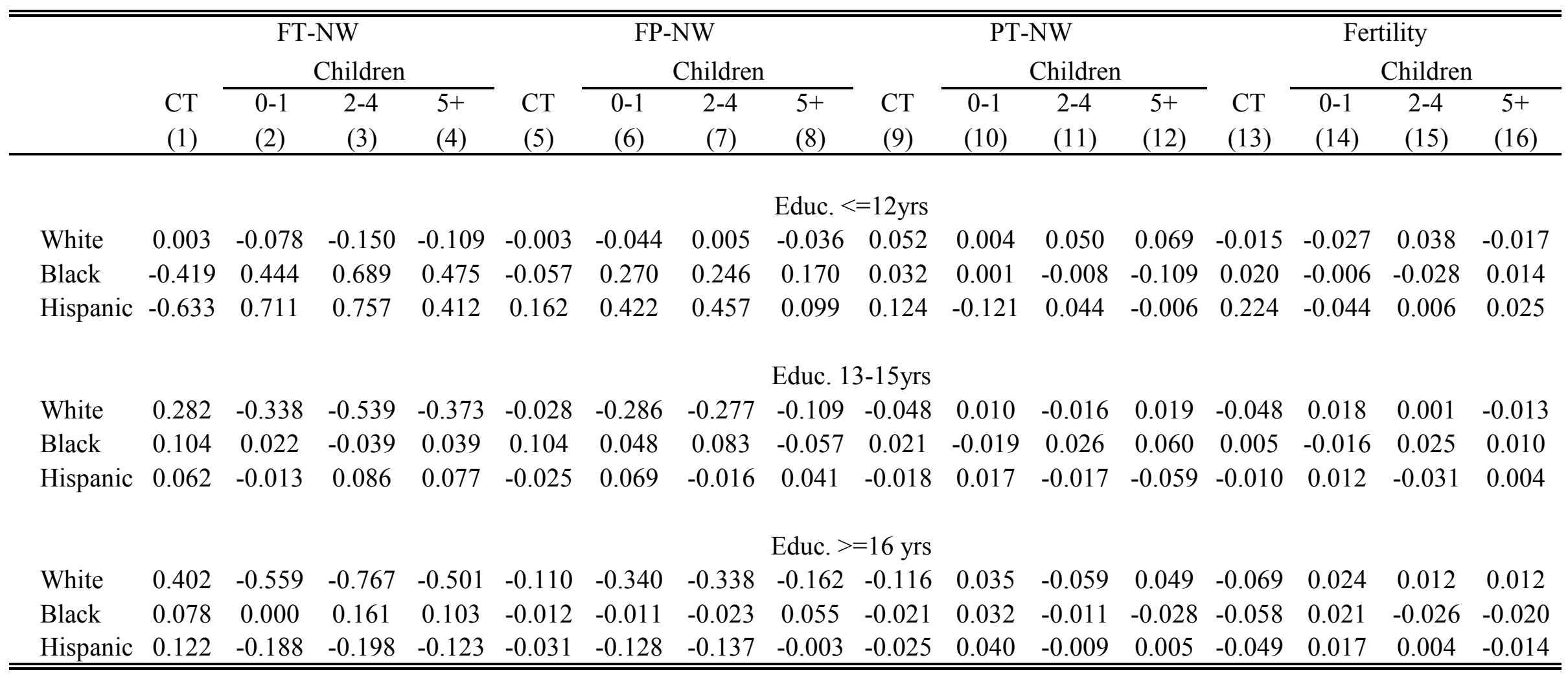

